\title{
The Comprehensive Assessment: What lessons can be learned?
}

\begin{abstract}
Analysing the database made available by the European Central Bank and by the European Banking Authority, we evaluate the Comprehensive Assessment (Asset Quality Review and Stress Test) of banks carried out in 2014. In a nutshell, the main results are: i) risk-adjusted capital ratios are negatively related to the Asset Quality Review shortfall, but not to the Stress Test shortfall, whereas the leverage ratio plays a significant role in both cases; ii) the Comprehensive Assessment predominantly concentrated on traditional credit activity rather than on banks' financial assets; iii) the Comprehensive Assessment seems to be characterized by double standards. The Asset Quality Review was severe with banks operating in non-core countries, while medium-sized banks were either riskier or were treated severely in both exercises. The analysis leads to a puzzle: comparatively, the assessment per se led to significant adjustments for solid banks and large shortfalls for weak banks. The puzzle can be resolved by referring to the legacy of the country's former supervisory activity and to the low level of capitalization of weak banks mostly in peripheral countries.
\end{abstract}

Keywords: bank regulation, stress test, capital, sovereign risk, European Central Bank

JEL codes: E58, E65, G21, G28 


\section{Introduction}

The Comprehensive Assessment (CA) performed by the European Central Bank (ECB) and the European Banking Authority (EBA) in 2014 marked an important step towards the European Banking Union. In autumn 2013, European institutions changed the banking supervisory system by establishing the Single Supervisory Mechanism (SSM) in the Eurozone. The publication of CA results, just few days before the start of the SSM, was intended to accomplish two main tasks: first, to define a level playing field, harmonizing different (national) approaches to bank supervision, and second to quantify the risks of European banks in order to determine an appropriate level of capitalization. ${ }^{1}$ The first task was mainly addressed through the Asset Quality Review (AQR) and the second through the Stress Test (ST) analysis based on two different scenarios: a baseline scenario and an adverse scenario.

The two exercises complement each other, but they were run in different ways. The AQR was performed by national supervisory authorities under the supervision of the ECB; this review led to an harmonization among national supervisory approaches and to $€ 48$ billion (bn) of adjustments to bank assets (ECB, 2014a). ${ }^{2}$ The two scenarios of the ST were country specific, the baseline scenario was derived from the European Commission's three year forecasts and the adverse scenario was obtained through a downward perturbation of the baseline scenario; the capital adjustment related to the adverse ST scenario was $€ 263$ bn yielding a median $4 \%$ reduction in the Common Equity Tier 1 (CET1) ratio (ECB, 2014a).

The literature on the CA is rather limited. There are papers aiming at establishing its capability to capture bank risk, $^{3}$ and papers studying the market reaction in terms of cumulative abnormal

\footnotetext{
${ }^{1}$ We recall that by the end of 2013 banking supervision was fully in the hands of national authorities and that the CA can be considered the first act of the ECB as a supervisory authority of the banking system. Before the CA, national authorities adopted different standards concerning the evaluation of assets/loans, the capital buffer (the quality/level of CET1 capital) and the implementation of Basel III (national discretion in the phase-in process).

${ }^{2}$ Harmonization concerned several issues, such as: the definition of non-performing exposures, impairment triggers, provisioning approaches for going concern non-performing exposures, collateral valuation, point-in-time collective provisioning and credit valuation adjustment calculation.

${ }^{3}$ We refer to Acharya and Steffen (2014) and Barucci et al. (2016) on the capability of the CA to effectively capture bank risk. Acharya and Steffen (2014) discovered that there is a negative relationship between the capital deficit determined by the CA and bank risk according to the benchmark adopted in their analysis (SRISK); if the total losses detected by the CA are considered, then the relationship turns out to be positive. They suggest that these contradictory results are mainly due to the use of risk weights in the regulatory capital benchmark and that the results can be reconciled by considering a pure leverage ratio for regulatory capital. Barucci et al. (2016) show that the CA's capital deficit is
} 
returns to the announcement of the results of the CA and to the publication of banks' shortfalls. ${ }^{4}$ Recently Fiordelisi et al (2017) have analysed the effect of the SSM on banks' lending: they show that banks subject to the SSM supervisory reduced their lending activity more than the other ones.

In this paper we analyse in detail the ECB's dataset published with the disclosure of CA definitive results. The assessment was followed by a debate concerning its capability to capture bank risk and the possibility of double standards with respect to banks' business models and their country of origin. Following the publication of CA results, there has been a discussion on the press, mainly in Italy, the European banking market with the largest capital deficit. After the disclosure of the CA, the former Italian prime minister and former president of the European Commission Romano Prodi said: "The referee whistled strangely. [...] I would be curious to know how the German Landesbank not included in the examinations would be judged». ${ }^{5}$ Even the Bank of Italy (2014) criticized some CA's hypotheses, underlying the fact that the adverse scenario implies a collapse of the Italian economy. ${ }^{6}$ Implicitly, they argued that core countries have benefited from a softer treatment, this criticism has also been renewed recently (see, e.g., Reuters, 2017). To the best of our knowledge, these issues have not been addressed in the literature. In what follows, we aim to identify the main lessons of the CA. In particular, our purpose is to evaluate its main drivers and to ascertain discontinuities with respect to the previous national regulatory/supervisory standards.

In this perspective, we investigate the determinants of the capital shortfall of a bank, considering two different measures: i) the shortfall with respect to the $8 \%$ CET1 ratio threshold after the AQR exercise, and ii) the shortfall under the ST in the adverse scenario with respect to the 5.5\% CET1 ratio threshold. The shortfall is provided by the absolute value of the threshold minus the capital

positively related to the volatility of a bank and therefore the CA seems to be aligned with a historical (backwardlooking) measure of a bank's riskiness.

${ }^{4}$ Two event study analyses (Sahin and de Haan, 2015; Carboni et al. 2017) examine the impact on banks' stock prices of CA announcements, on the 23 October 2013, and of CA results, on the 26 October 2014. They consider the subset of listed banks. Sahin and de Haan (2015) find heterogeneity in cumulative abnormal returns across countries in the Euro area, instead Carboni et al. (2017) find that banks under direct ECB supervision registered a more negative market reaction with respect to banks maintaining national supervisors.

${ }^{5}$ Our translation from Italian. The statement is taken from Corriere della Sera, one of the main Italian daily newspapers (Massaro, 2014).

${ }^{6}$ Other CA characteristics have been criticized by the governor of Bank of Italy, Ignazio Visco. In front of the Italian Parliament he declared «stress test results were strongly affected by partial removal of the possibility of sterilizing through a special prudential filter - the effect of changes in the value of sovereign bonds [...] However, no "harmonization" of other national discretions was made [...] then it was adopted, with a decision that we have not shared and challenged in a formal way, an asymmetric approach to the national discretion» (Visco, 2014, pp. 6-7. Our translation from Italian). 
ratio after the exercise floored at zero. Our main findings are as follows: a) the outcome of the CA was biased against banks specialized in traditional activity; b) the leverage ratio performs better than the CET1 ratio in capturing the shortfall of the ST; c) the shortfall seems to depend on the legacy of national regulatory/supervisory activity.

As can be noticed from a purely descriptive analysis, the AQR concentrated predominantly on traditional credit activity rather than on the assets detained by banks: only $€ 1.4$ bn of the AQR adjustments were due to asset evaluation adjustments, while $€ 3.1$ bn came from the revision of credit valuation adjustment (CVA) values and €43 bn came from credit adjustments (ECB, 2014a). This evaluation is confirmed by our analysis: the AQR shortfall and the ST shortfall are positively affected by the role of credit activity, but are not influenced by the presence of financial assets evaluated at fair value, even when they are extremely difficult to evaluate (level 3 assets).

Our analysis sheds some light on the banking capital dispute. As expected, the AQR shortfall is negatively affected by the CET1 ratio and by the leverage ratio; however, we show that the ST shortfall is only affected by the leverage ratio. These results suggest that the ECB and the EBA do not recognize manipulation in the risk weights, but in any case a pure leverage ratio was able to capture bank's risks (as an outcome of the stress tests) better than a risk-adjusted capital ratio. This result reinforces the scepticism concerning the reliability of risk-weighted capital ratios following the financial crisis (for European stress tests in 2011 and in 2014, see e.g. Acharya et al., 2014; Acharya and Steffen, 2014; EBA, 2011; Haldane,2012). ${ }^{7}$

Our results provide some evidence that the shortfall of the AQR and of the ST depends on the country in which the bank group is incorporated. Banks located in peripheral countries were treated severely in comparison to those of core countries. ${ }^{8}$

These results on the shortfall are not easy to interpret because of the interplay of two different arguments: the design of the AQR and of the ST, the starting level of capitalization of banks. As a matter of fact, a bank with certain features may end up with a significant SF either because of the

\footnotetext{
${ }^{7}$ Scepticism was reinforced by the fact that the large variation observed in the risk-weighted assets was not driven by banks' business models or risk profiles: there thus remains room for supervisory and managerial practices (see Basel Committee on Banking Supervision, 2013a, 2013b; Cannata et al., 2012; EBA, 2013; Haldane, 2011; Le Leslé and Avramova, 2012).

${ }^{8}$ Hereinafter, we assess the supervisor's activity as soft (severe) towards a set of banks when, considering also a set of controls for other features, there is a low (large) impact in terms either of shortfall or of adjustment (CET1 reduction as a result of the exercise).
} 
design of the CA or because the bank was undercapitalized. To evaluate the two different hypotheses, we go through the analysis of the adjustments, i.e., the difference in the CET1 ratio before and after the CA's tests. In this case the initial capital ratio doesn't play any role and therefore the analysis is only about the design of the CA. The results for the adjustments of the ST are striking: banks with good credit quality (low non-performing loans) and less leveraged were affected by greater adjustments. This evidence suggests that the CA was softer towards riskier/weaker banks.

As the evidence concerning the capital shortfall and that related to the adjustment partly goes in opposite directions, we can conclude that the dependence of the shortfall on some banks' features is not due to the design of the assessment, in particular of the ST. The puzzle seems to be mostly related to the low starting capital buffer for banks characterized by poor credit quality and located in non-core countries.

The paper is organized as follows. In Section 2 we describe the database and the empirical model. In Section 3 we present our main results on the shortfall of the AQR and of the ST. In Section 4 we provide further evidence and in Section 5 we provide an analysis of the adjustments to discern among the different hypotheses behind the results. Section 6 concludes.

\section{Data set and empirical model}

We analyse bank-level data from the ECB with respect to adjustments and shortfalls after the AQR and the ST. The CA involved 130 banks for the AQR with total assets of €22 trillion (tr) and riskweighted assets (RWAs) of $€ 8.5 \mathrm{tr}$, which account for $81.6 \%$ of the banking system under the umbrella of the SSM (for the complete list of banks, see ECB, 2014b); 103 of these financial institutions were also involved in the ST analysis. ${ }^{9}$ The AQR focused on bank assets as at the end of 2013, while the ST performed a scenario analysis on a three-year window up to 2016. Our sample is made up of 129 banks operating in the euro area (see Table 1), using the dataset provided by the ECB. ${ }^{10}$ The dataset includes some general information on bank accounts before and after the CA

\footnotetext{
${ }^{9}$ The difference between AQR and ST samples is due to banks controlled by large banking groups ( 25 cases) and by two main clearing houses.

${ }^{10}$ We omit data from Deutsche Bank Malta because of the abnormal CET1 ratio (281\%).
} 
(sections $A, B, C$ and $F$ ) and a breakdown of credit exposure, CVA and the level 3 component of market exposure (section D). Furthermore, related to banks' credit exposure, the ECB also provides a detailed analysis of non-performing exposures (NPEs) and coverage ratio (CR) of NPEs in section E. ${ }^{11}$ We also take into consideration data from the EBA with respect to credit risk and the market risk relevant to the ST.

[Insert Table 1 about here]

Total gross loans over total assets in 2013 are from the Bankscope database while the stock exchange market capitalizations and the gross domestic product (GDP) figures are 2013 values from the World Bank database. Definitions and descriptive statistics of all the variables used in the empirical analysis are reported in Table 2. In Table 3 we report the mean value of the main variables by country.

\section{[Insert Tables 2 and 3 about here]}

Our research strategy is to estimate the shortfall of a bank associated with the AQR threshold and the shortfall associated with the ST under the adverse scenario. ${ }^{12}$ In what follows, we refer respectively to the two shortfalls as $S F_{-} A Q R$ and $S F_{-} S T$. The capital shortfalls are obtained as the absolute value of the differences (floored at zero) between the CET1 ratio obtained after the AQR and after the ST and the associated thresholds ( $8 \%$ for the AQR and 5.5\% in 2016 post ST under the adverse scenario). Note that the shortfall is strictly positive if the bank didn't pass the assessment and zero otherwise. ${ }^{13}$

The focus of the CA on the CET1 ratio to assess the potential shortfall of a bank implies that this risk-weighted capital-asset ratio should well represent bank risks. A pure descriptive analysis provides mixed evidence. Looking at the bivariate relation between the ratio of non-performing exposures over total exposures and the CET1 ratio (both measured before the CA), we find only a

\footnotetext{
${ }^{11}$ In ECB (2014c), a NPE is defined as i) "every material exposure that is 90 days past due even if it is not recognised as defaulted or impaired"; ii) "every exposure that is impaired"; iii) "every exposure that is in default according to CRR". $\mathrm{CR}$ is defined as the ratio between the specific or collective allowances for losses incurred or not incurred and the NPE.

${ }^{12}$ We also considered as dependent variable the shortfall of the CA as a whole which is given by the maximum of the shortfalls of the AQR, of the ST under the baseline scenario and of the ST under the adverse scenario. We obtained results similar as in the case of SF_ST and as a consequence we omitted them.

${ }^{13}$ We opted to consider SF as our dependent variable, instead of the uncensored buffers after the CA, because under the CA's rules the bank has to submit a detailed plan on how to fill the capital gap only in the case of a positive SF, while for close to zero buffers no actions are required.
} 
mild negative link (Figure 1). However, as expected, the relation between CET1 ratio (measured before the $C A$ ) and the capital shortfalls associated with the AQR and the ST shows that the shortfalls are mainly concentred on the banks with lower starting point levels of CET1 ratio (Figure 2).

[Insert Figures 1 and 2 about here]

To deeply investigate the determinants of the shortfalls, we run a multivariate analysis. As determinants of the shortfalls, we consider a set of exogenous variables that are available from the ECB and EBA database and other sources. We start with the following reference model:

$$
\begin{gathered}
\text { SF_Y } Y_{\mathrm{i}}=k+\beta_{1} \cdot \operatorname{cet}_{i}+\beta_{2} \cdot \text { lr }_{i}+\beta_{3} \cdot \text { Dmediumsize }_{i}+\beta_{4} \cdot \text { Dlargesize }_{i} \\
+\beta_{5} \cdot \text { npe }_{i}+\beta_{6} \cdot \text { cr }_{i}+\beta_{7} \cdot \text { sys }_{i}+\beta_{8} \cdot \text { marketcap }_{j}+\beta_{9} \cdot \text { level }_{i} \\
+\beta_{10} \cdot \text { Drestruct }_{i}+\beta_{11} \cdot \text { Dirb }_{i}+\varepsilon_{i}
\end{gathered}
$$

where $S F_{-} Y_{i}$ denotes the AQR or the ST shortfalls of bank $i$, expressed in euro bn. ${ }^{14}$ In the model we include two types of exogenous variables: bank-specific variables (lower case $i$ ) and a countryspecific variable (lower case $j$ ) that refers to the country in which the bank holding company is located. The correlation matrix for the exogenous variables is reported in Table $4 .{ }^{15}$

\section{[Insert Table 4 about here]}

We control for the size of the bank by introducing two dummy variables: ${ }^{16}$ i) Dmediumsize, which is equal to 1 if total assets of bank $i$ are larger than the first quartile and lower than the third one and to 0 otherwise; ii) Dlargesize, which is equal to 1 if total assets of bank $i$ are larger than the third quartile and to 0 otherwise. Bank size provides a control variable for the level of the shortfall:

\footnotetext{
${ }^{14}$ As a robustness test, we also considered the logarithm of the SF_AQR and of the SF_ST expressed in euro millions, imposing a minimum value of zero for banks recipient of a null shortfall. We also estimated equation (1) considering a logit model with a dichotomous $(0,1)$ endogenous variable depending on whether the shortfall was null or positive. We obtained results similar to those presented below and therefore they are omitted.

${ }^{15}$ As reported in Table 5, a positive shortfall is observed in 16 (23) banks for the AQR (ST) over a sample of 129 observations. The limited number of non null observations may conflict with the number of covariates (10/11 depending on the model considered). To cope with this issue, we also estimated more parsimonious versions of our empirical model. The main results are robust to this test. More specifically, we considered a more parsimonious model for the shortfalls with only four explanatory variables (cet1/lr, npe, cr, sys) or five (with loan). We also considered a different set of four explanatory variables (npe, $c r$, sys, 1-Dcore) and the interaction between Dcore and cet1, Ir and npe, respectively. Results are available on request.

${ }^{16}$ We include dummy variables and not the level of total assets in order to limit the multicollinearity problem with other exogenous variable.
} 
ceteris paribus, the shortfall is likely to be affected positively by the size of the balance sheet. ${ }^{17}$ The attitude of the supervisory authority towards a bank may depend on its size for several reasons: on the one hand, a large bank is more likely to be supervised by the market and therefore the need for intervention from the supervisory authority should be less intense; on the other hand, a large bank is riskier from a systemic risk perspective, thus potentially making supervision softer or more severe. To investigate further how the bank's relevance affects the CA exercise, we also consider the ratio of the assets of the bank over the nominal GDP of the country in which the bank is incorporated (sys). This ratio should explicitly capture the systemic relevance associated with a bank in terms of the relationship between size and systemic risk (see e.g. Laeven et al., 2014).

The dispute concerning the risk-weighted capital requirement leads us to introduce the CET1 ratio (cet1) as an exogenous variable. If the capital ratio is a reliable indicator of the bank's solidity, it should have a negative effect on the size of the shortfall for the AQR and for the ST. Note that the shortfalls are defined with respect to CET1 ratio thresholds and thus (in a mechanical way) a lower shortfall should be associated with a higher CET1 ratio as a starting point (both for the AQR and for the ST). The denominator of the capital ratio is made up of RWAs, which implies that banks detaining risky assets are obliged to detain a large amount of capital. Therefore, if the RWA computation effectively reflects the riskiness of assets, banks with a higher capital ratio should also be more resilient to shocks and therefore the shortfalls of the AQR and of the ST should be smaller.

According to the Basel II/III framework, if regulatory and supervisory activities work properly, then the CET1 ratio should provide exhaustive information about the soundness of the bank and other indicators of capital solidity should be redundant. To evaluate this point, we also consider the leverage ratio computed as CET1 capital over total assets (Ir) and measured according to the Capital Requirements Regulation (CRR) under the Capital Requirements Directive (CRD). It should be noted that the dispute on risk-adjusted versus non-risk-adjusted capital ratios is not settled and it is difficult to establish which type of capital ratio captures the riskiness of a bank to a greater extent. ${ }^{18}$

\footnotetext{
${ }^{17}$ Another way of addressing this size effect would be to consider the shortfall in terms of basis points (bps). We opted to present our results for the level of the shortfall rather than for the basis point shortfall because in the latter case the capital is at the denominator yielding a possible bias with the exogenous variables that are also related to capital. Nevertheless, we also performed regressions for the SF in bps and the main results obtained in our analysis are confirmed.

${ }^{18}$ The evidence in the literature is mixed. There is some evidence showing that a higher Tier1 capital ratio negatively affected the probability of recapitalization/state aid during the financial crisis (see Bayazitova and Shivdasani, 2011;
} 
To fully investigate the CA, we analyse how the composition of the balance sheet affects the shortfall. Credit quality is considered including the ratio of non-performing exposures over total exposures (npe) and the coverage ratio for non-performing exposures (cr), i.e. the ratio between credit loss provision funds and non-performing exposures. As far as the asset component is concerned, we consider the proportion of level 3 assets to total assets (level3). ${ }^{19}$ Note that if RWAs adequately assess risks, then these variables should not affect the shortfall.

For the country-specific variables, we consider stock exchange market capitalization over nominal GDP (marketcap). Our goal is to control for a market discipline effect that may substitute supervisory scrutiny: banks located in a well-developed financial market may be characterized by lower AQR and ST shortfalls because the market has already imposed impairments and adequate capitalization/risk management. ${ }^{20}$

We complete our analysis by inserting the dummy variable Drestruct, which takes a value equal to 1 in the case of a bank undergoing a restructuring process before 31 December 2013 and 0 otherwise. A restructuring plan for a bank is usually accompanied by an intense activity by the supervisory authority, deleveraging/cleaning of the books and public or private capital injections. Thus, this variable should allow us to control for capital deficiencies before the 2014 CA. ${ }^{21}$

Banks may choose to evaluate risk weights according to an internal model instead of the standard formula. To capture this feature, we include the dummy variable Dirb, which takes a value equal to 1 in the case of a bank with more than $50 \%$ of its RWAs computed according to the internal rating model (a value quite similar to the median in the sample analysed) and zero otherwise. We expect a negative effect from this variable on the CA's shortfall if the supervisor is not confident about the

\footnotetext{
Mariathasan and Merrouche, 2012). Some other papers show that a higher capital ratio (but also a higher leverage ratio) was related to better market performance during the crisis (Beltratti and Stulz, 2012;Das and Sy, 2012; DemirgüçKunt et al., 2013). Vallascas and Hagendorff (2013) find a statistically significant relationship between risk density (riskweighted assets over assets) and bank volatility. As far as predicting bank distress is concerned, Betz et al. (2013) and Haldane (2012) show that leverage has greater predictive power than risk-weighted asset measures, whereas Estrella et al. (2002) show that their performance is similar (with a preference for the leverage ratio).

${ }^{19}$ According to the International Financial Reporting Standards (see IFRS 13), level 3 assets are those assets that need to be valued using models (mark-to-model) in the absence of observable market data.

${ }^{20}$ We also controlled for the performance of the national economy including GDP growth; the variable turned out to be strongly correlated with balance sheet indicators of credit quality and for this reason we opted to eliminate this variable.

${ }^{21}$ To check whether the effect of Drestruct could be due to an endogeneity effect, we ran a robustness test in which all the banks under restructuring plans ( 24 institutions) were excluded from the analysis. The main results are confirmed.
} 
capacity of internal models to capture the riskiness of banking activities and/or suspects manipulation of risk weights. ${ }^{22}$

We estimate equation (1) using a Tobit estimator, which overcomes the problem of inconsistent results derived from using the ordinary least squares estimator when the dependent variable is censored, see Wooldridge (2002). As suggested by Cameron and Trivedi (2005), we check for distributional misspecification in the error terms. In the estimation outputs we report the LM test of the Tobit specification, which checks for linearity, homoskedasticity and normality assumptions.

\section{Empirical analysis}

The reference model is estimated and the results are reported in Table $5{ }^{23}$

\section{[Insert Table 5 about here]}

As first step, we consider a restricted version of equation (1). We include the CET1 ratio and the leverage ratio separately, respectively in models I and IV and in models II and V with regarding to $S F_{-} A Q R$ and $S F_{-} S T$. Collinearity does not emerge in any model using both a variance inflation factor (VIF) diagnostic and a condition index. ${ }^{24}$ However, models II and IV do not pass the LM test of Tobit specification at the $10 \%$ level of confidence, suggesting that the Tobit specification is unsuitable. Thus, in what follows, we do not comment the results for models II and IV.

cet1 negatively affects the shortfall of the AQR (model I), Ir negatively affects the shortfall of the ST (model V). In models III and VI, we estimate equation (1) without restrictions (both cet1 and Ir are

\footnotetext{
${ }^{22}$ There is considerable evidence showing that banks use the discretion of Basel II agreements (mostly the internal rating-based approach) to reduce RWAs (see Beltratti and Paladino, 2013; Benh et al., 2014; Mariathasan and Merrouche, 2014). According to their interpretation, banks exploit the flexibility of the internal model of Basel II to underestimate their risks, see also Le Leslé and Avramova (2012) and Das and Sy (2012). Accounting standards provide a further source of manipulation: Huizinga and Laeven (2012) and Bushman and Williams (2012) document accounting discretion during the financial crisis by banks. The Basel III system allows country-specific discretionary measures in the phase-in period, which may introduce a further "manipulation" at the country level.

${ }^{23}$ In Table 5, and in the following tables, we report the pseudo R-squared which is equal to 1 minus the ratio between the full model log-likelihood and the constant-only one, as evaluated by "tobit" instruction in Stata13. Note that pseudo $\mathrm{R}$-squared should be considered with caution in case of Tobit regressions also because it can give values lower than 0 and higher than 1 (see e.g. Wooldridge, 2002, p. 529).

${ }^{24}$ As rule of thumb for VIF (condition index), we consider a conservative level of 2.5 (15), while values greater than 5 (30) indicate high correlation and are cause for concern. Values between the two levels show evidence of moderately correlated variables.
} 
included). The inclusion of both capital ratios does not create concern about multicollinearity. As expected, we find that a high CET1 ratio negatively affects the shortfall of the AQR (model III) ${ }^{25}$ : on average, adding one percentage point of cet1 implies a $€ 0.10$ bn lower shortfall. ${ }^{26}$ On the other hand, the leverage ratio turns out to be not significant. Considering $S F_{-} S T$, the results are reversed: the relationship with cet 1 is not confirmed, while the Ir coefficient is negative and highly significant (model VI). An additional one percentage point of Ir implies, on average, a $€ 0.60$ bn lower shortfall after the ST.

These results suggest that a high CET1 ratio allowed to escape a shortfall after the revision of the balance sheet by the ECB through the AQR. This outcome seems to signal that the ECB and the EBA did not detect risk weight manipulation. This interpretation is confirmed by the coefficient associated with the dummy variable measuring whether a bank relies on the internal rating approach (Dirb), which negatively affects the shortfall of the AQR, while the variable is not significant when the SF_ST is considered. From this evidence, we can deduce that according to the $\mathrm{CA}$, the adoption of the internal-based model is not associated with risk weight manipulation.

On the other hand, when the shortfall of the ST is analysed we observe that a high CET1 ratio doesn't guarantee the bank to end up above the threshold after the ST. Instead a high leverage ratio allows to pass the ST. This outcome could be due to the static balance sheet assumption made in the ST, which implies that banks maintain the same business mix and model throughout the time horizon. Under this assumption, any mitigating action by banks is precluded. Therefore, the impact of the ST is likely to be parametrized to total assets, and therefore to the leverage ratio, rather than to risk weighted assets and therefore to CET1 ratio.

Taking into account the unrestricted version of equation (1), we observe that both Dmediumsize and Dlargesize variables have a positive and significant effect on SF_AQR (model III). On the other hand, we find that only Dmediumsize coefficient, but not the one of Dlargesize, is positive and significant when SF_ST is considered (model VI). The fact that large banks were not considered

\footnotetext{
${ }^{25}$ To check whether the results related to cet1 are mainly driven by a mechanical effect, due to the choice to focus the CA on thresholds based on CET1 ratio, we consider a dummy variable which is equal to 1 if a bank has a CET1 ratio higher than the median value at the country level and 0 otherwise. In this way, we introduce nonlinearity in the exogenous variable. As the main results are confirmed, we can affirm that the mechanical factor is not the unique explanation for the results.

${ }^{26}$ The marginal effects, here and in the rest of the paper, are evaluated on the unbounded dependent variables (see Cong, 2000).
} 
riskier by the ST (and therefore by the CA as a whole) is confirmed by the negative and significant coefficient associated with the variable capturing the systemic nature of the bank (sys). These results can be interpreted in different ways. It may be that supervisors are captive to large banks or that large banks were able to evaluate their assets more carefully or possibly were subject to greater supervision after the Lehman Brothers default because of the "too big to fail" problem. Supervision by the market (of large banks) may also be the root of the results. As a matter of fact, a well-developed financial market (represented by the variable marketcap) negatively affects both $S F_{-} A Q R$ and $S F_{-} S T$. This result could be related to the role of market supervision (Basel II/III's third pillar), which complements the activity of the supervisory authority (Basel II/III's second pillar).

Looking at the composition of the balance sheet, we observe that the shortfall both of the AQR and of the ST is inflated by the ratio of non-performing loans, representing an indicator of the quality of credit. Lower quality (higher ratio) induces a more significant shortfall. The phenomenon is balanced by the fact that a high coverage ratio of non-performing loans negatively affects the shortfall of the AQR, while in the case of ST the effect is not significant. It seems that national authorities and the ECB recognized provisions as a safeguard for non-performing exposures, which were not able to help to attain a positive buffer after the ST. Surprisingly, the proportion of level 3 assets over total assets does not affect the shortfall of either the AQR or the ST. This outcome and the fact that the adjustments associated to level-3 assets are mostly negligible and concentrated in a few banks, ${ }^{27}$ suggest that the CA failed to capture their risks and to provide a critical analysis of the value of assets and derivatives.

The role of restructuring plans (Drestruct) is significant and robust as the specification varies: a bank under restructuring is characterized by a higher shortfall of the AQR ( $€ 0.5$ bn on average) and of the ST (€1.0 bn).

\section{Further evidence}

\footnotetext{
${ }^{27}$ For example, the total impact on derivatives was only $€ 0.2$ bn, $60 \%$ of which was due to just one institution (Banque populaire Caisse d'Epargne).
} 
In what follows, we consider the unrestricted model and we further analyse the results of the CA. We develop our analysis in two directions: i) examining the risk composition of the balance sheet and ii) comparing banks by country of origin.

In Table 6 we investigate how the RWA composition affects $S F_{-} A Q R$ and SF_ST. We consider three different measures of balance sheet composition: i) risk density, i.e. RWAs over total assets ( $r w a)$, where a higher ratio signifies that the assets are riskier; ii) the share of total gross loans over total assets (loan); ${ }^{28}$ the overall exposure (credit and government bonds) to the country where the bank is incorporated over total exposure (homebias). ${ }^{29}$

\section{[Insert Table 6 about here]}

We observe that the rwa coefficient is positive and statistically significant when $S F_{-} A Q R$ is considered (model I). Considering the shortfall associated with the ST, we find that the model IV do not pass the LM test of Tobit specification at the $10 \%$ level of confidence, suggesting that the Tobit specification is unsuitable. It seems that the riskiness of the assets drives the shortfall associated with the AQR, but we cannot draw conclusions about the effect of rwa in the ST. Instead, both $S F_{-} A Q R$ and SF_ST are affected by loan (models II and V) and are not affected by the share of total exposure to the country in which the bank is located (model III and VI). We interpret these results as evidence that credit specialization is associated with a higher shortfall in the CA, but there is no evidence of home bias.

As mentioned in the introduction, the CA exercise was followed by a debate about the possibility that the ECB and the EBA adopted double standards with respect to banks depending on their country of origin; to address this point, we provide some regressions considering among the exogenous variables a dummy variable (Dcore), which assumes a value equal to 1 in the case that a bank is incorporated in one of the core countries (Austria, Belgium, Germany, Finland, France, Luxembourg and the Netherlands) and 0 otherwise (peripheral countries). In Tables 7 and 8 we provide some regressions for $S F_{-} A Q R$ and $S F_{-} S T$, respectively.

\footnotetext{
${ }^{28}$ We exclude banks with loan higher than 1 from the sample. However, results are robust to the inclusion of these observations.

${ }^{29}$ We also considered i) the gross exposure to government bonds of the country where the bank is incorporated over total gross government exposure and ii) the ratio of corporate and retail credit risk exposure over total credit risk exposure and the assets in the banking book. We omit regressions with these exogenous variables because they are either weakly statistically significant or not significant.
} 
[Insert Tables 7 and 8 about here]

We introduce the variable 1-Dcore and then we interact Dcore and 1-Dcore with four different exogenous variables: i) CET1 ratio; ii) leverage ratio; iii) non-performing exposure; iv) coverage ratio. To check whether the effect of the variable for core countries is statistically different from that of non-core ones, we report the derivative of the dummies that represent the two groups of countries.

First of all, we observe that the effect of the 1-Dcore variable, without interactions, on the shortfall of the AQR is positive and significant (Table 7, model I), while it is positive but not significant for the shortfall of the ST (Table 8, model I). This evidence suggests that banks located in non-core countries were characterized by adjustments in the AQR that induced a higher shortfall. This implies that either the adjustments were higher or the CET1 starting point was lower compared to other countries, or both.

Looking at the interaction of Dcore and 1-Dcore with the exogenous variables we observe that in case of SF_AQR the absolute values of the coefficients associated with banks incorporated in core countries are higher than the coefficients associated with banks incorporated in non-core countries. A high CET1 ratio (model II) for a bank of a core country negatively affects the shortfall more than in the case of a bank of a peripheral country. With respect to non-performing exposures, we find that the effect is positive and significant in the case of peripheral countries, while it is negative and weakly significant for core countries (model IV). We also observe that the effect of the coverage ratio in core countries is negative and significant, while in peripheral countries it is not significant (model V). Moreover, we find that the marginal effect of bank with the headquarter in a core country, evaluated at the median value of interacted variables, is always negative and significant in the case of the interaction with cet1, npe and $c r$. In the case of peripheral countries, the derivate is negative and significant only for the interaction with cet1 and $c r$, with a magnitude lower than for the core countries.

These results can be interpreted in two different ways: either as a signal national authorities in peripheral (core) countries were soft (severe) towards domestic banks before the CA exercise, or as evidence that the AQR was soft (severe) towards banks incorporated in core (non-core) countries. 
The above results are not confirmed for SF_ST with the exception of the leverage ratio (Table 8, model III). This evidence suggests that the AQR was more severe (softer) with banks based in peripheral (core) countries, but there is no evidence concerning the ST. As a result, we may conclude, according to AQR, that banks in core countries either were better capitalized or were evaluated with cleaner balance sheets than those of other countries. In any case there is no evidence that the adverse ST scenario was more severe for peripheral countries.

\section{A closer look at the determinants of the shortfall}

In order to further investigate the determinants of the shortfall of the CA and in particular the role of the country of origin, we estimate (1) for the adjustments of the AQR (ADJ_AQR) and of the ST (ADJSST). In both cases we consider the adjustments over RWA. The difference between adjustments and shortfalls is that the former figures are obtained as the difference between the capital before and after the two exercises (AQR and ST); the latter are obtained as the positive part of the difference between a threshold ( $8 \%$ for AQR and 5.5\% for ST in the adverse scenario) and the capital obtained after each exercise. As a consequence, the results on the shortfall depends on the starting level of capitalization of a bank while those on the adjustments do not. Therefore, looking at the results for the determinants of the adjustments and of the shortfalls we may provide insights into the level of capitalization before the CA and the design of the exercise.

Regressions on the adjustments, based on the OLS estimator, are provided in Table 9. The analysis of the AQR shows weak evidence of bank-specific factors affecting the adjustment. As there is no reference to a threshold for the CET1 ratio, only cet1 is weakly significant in estimating the AQR adjustment (model I), while after adding $r w a$ among regressors both cet1 and $I r$ are not significant (model II). Two main results observed in the shortfall analysis are confirmed: $A D J A Q R$ is negatively affected by the capitalization of the stock exchange and is positively affected by the proportion of non-performing exposures. We can conclude that a poorer quality credit and a weaker supervision by the market are associated with a larger adjustment in the AQR.

\section{[Insert Table 9 about here]}

The picture changes significantly analysing the adjustment of the ST as a whole (models III-IV). First of all, the adjustment is larger in case of large banks, moreover both the cet1 and the Ir positively 
affects (with a statistically significant coefficient) the adjustment. Notice also that banks with a large proportion of non-performing exposures are characterized by small adjustments, and the level of market capitalization positively affects the adjustment of the ST. ${ }^{30}$

From the evidence on the determinants of the adjustments of the ST, we can conclude that the ST was severe towards banks with high leverage/capital ratio, and therefore in a safer capital position and with good quality of credit. These results contrast with those obtained for the shortfall. It seems that the assessment was much more severe with solid banks than with banks in a weak condition; nevertheless, weaker banks were assigned higher shortfalls.

The above results leave us apparently with a puzzle: on the one hand, the adjustment analysis shows that the ST was severe towards good banks, but on the other hand, these banks were indeed recipients of a small shortfall. Despite the soft approach of the ST towards weak banks in terms of adjustments, they ended up with a level of capital below the threshold with a significant shortfall. As a consequence, we can exclude the possibility that the final outcome was due to bias/extreme hypotheses of the ST. It seems that as in the case of the 2010 and of the 2011 exercise (see Greenlaw et al., 2012), the European STs run in 2014 appear too soft and allow for too much discretion. We can conclude that the CA's results in terms of capital shortfalls are mainly driven by heterogeneity in the CET1 ratio starting point: banks with a riskier profile were also characterized by a lower initial capital buffer, as also shown by the bivariate relationships represented in Figures 1 and 2. Relating this interpretation to the double standards apparently detected with respect to banks belonging to a core versus a non-core country, which affect the shortfall but not the adjustment, we may deduce that the capital buffer of weak banks located in peripheral countries before the CA was not well calibrated. In other word, our evidence rejects the hypothesis that the EBA and the ECB applied different standards among banks depending on their location.

From this perspective, we can positively assess the harmonization of the different national approaches provided by the CA as a first step of the European Banking Union. The SSM should render the European banking system more resilient reducing the risk of political capture of regulators across Europe, both in the core and periphery countries (Beck, 2014).

\footnotetext{
${ }^{30}$ These models do not show any evidence of significant multicollinearity. However, when cet1, Ir and rwa are simultaneously inserted as explicatory variables (models II and IV), results are weaker as signalled by the condition index.
} 


\section{Conclusion}

The results of the CA raised a number of questions related to the fact that it was not neutral. In particular, two issues were discussed in the broad debate that has followed the publication of CA results: i) the CA was severe towards banks located in peripheral countries; ii) the CA was biased towards traditional credit activity.

The analysis of the shortfall of the CA provided in this paper highlights that some factors affect the result besides the CET1 ratio starting point: i) banks located in non-core countries showed higher AQR shortfalls; moreover, ST was severe towards medium-sized banks in the sample; ii) poor credit quality and credit specialization are the main balance sheet features driving the shortfall, while the proportion of assets that are difficult to be evaluated plays no role. Moreover, we find that the CET1 ratio is significant in explaining the shortfall of the AQR, but not in explaining the shortfall of the ST. On the other hand, we find evidence that a less leveraged bank would experience a lower shortfall both in the ST.

An analysis on CA adjustments has allowed to conclude that the assessment's outcome was mainly driven by the heterogeneity in the capital buffer by the end of 2013. It seems that banks with poor credit quality and/or located in peripheral countries were also characterized by a lower initial capital buffer. This feature resulted in a higher shortfall. As a consequence, and looking at the overall CA's results, the hypothesis of a double standard applied by the EBA and the ECB depending on the location of banks should be rejected.

Our analysis provides three main policy implications. First, it shows that by the end of 2013 there was a significant degree of heterogeneity among national regulatory/supervisory standards; in this context the CA and the European Banking Union aiming to build a level playing field in the banking sector mark an important step towards a unique financial market and an effective monetary policy.

Second, our analysis of the CA outcome shows that the introduction of the leverage ratio in the new Basel III regulation is appropriate, as it transpires that a non-risk-adjusted capital measure is more closely related to capital shortfalls of stress tests than risk-adjusted capital measures. Moreover, our analysis shows that there is little evidence that CA was severe towards banks that adopted internal models. As the actual Basel III criteria on the leverage ratio appear rather light 
(see Basel Committee on Banking Supervision, 2015), the suggestion is to set a sharper constraint on the leverage ratio.

Finally, this paper also suggests that ECB supervision needs to take a step forward in two directions: attention is still too concentrated on traditional credit activity rather than on financial assets and the design of the STs seems to be inadequate. Considering all these aspects, some doubts emerge about the capability of the CA to guarantee a sound European banking system. From this perspective, the Supervisory Review and Evaluation Process (SREP), promoted by the EBA (2014) and ECB from 1 January 2016, seems to be a useful step as the experience of the Federal Reserve (2015) suggests.

However, it should be remarked that our empirical analysis is based on a small sample of banks, even if it is large enough to represent the most part of the European banking market, and with balance sheet data referring to just one year (2013). In the next future, the EBA and the ECB should disclose more information on a larger sample of institutions to give the opportunity to have a more precise view of the effect of EU-wide stress tests and of the SREP on European financial stability. 


\section{References}

Acharya, Viral, Engle, Robert and Pierret, Diane (2014) Testing macroprudential stress tests: the risk of regulatory risk weights, Journal of Monetary Economics, 65: 36-53.

Acharya, Viral and Steffen, Sascha (2014) Benchmarking the European Central Bank's asset quality review and stress test: a tale of two leverage ratios, VOX, November 2014.

Bank of Italy (2014) Results of the Comprehensive Assessment, press release available on https://goo.gl/ajWzNP.

Barucci, Emilio, Baviera, Roberto and Milani, Carlo (2016) Is the Comprehensive Assessment able to capture banks' risks?, Finance Research Letters 19: 98-104.

Basel Committee on Banking Supervision (2013a) Regulatory consistency assessment programme (RCAP) - Analysis of risk-weighted assets for credit risk in the banking book, mimeo.

Basel Committee on Banking Supervision (2013b) Regulatory consistency assessment programme (RCAP) - Analysis of risk-weighted assets for market risk, mimeo.

Basel Committee on Banking Supervision (2015) Basel III, monitoring report, mimeo.

Bayazitova, Dinara and Shivdasani, Anil (2011) Assessing TARP, Review of Financial Studies, 25: 377407.

Beck, Thorsten (2014) After AQR and stress tests - where next for banking in the Eurozone?, VOX, November 2014.

Beltratti, Andrea and Stultz, René M. (2012) The credit crisis around the globe: why did some banks perform better, Journal of Financial Economics, 105: 1-17.

Beltratti, Andrea and Paladino, Giovanna (2013) Why do banks optimize risk weights? The relevance of the cost of equity capital, mimeo.

Behn, Markus, Haselmann, Rainer and Vig, Vikrant (2014) The limits of model-based regulation, mimeo.

Betz, Frank, Oprica, Silviu, Peltonen, Thomas and Sarlin, Peter (2013) Predicting distress in European banks, Journal of Banking \& Finance, 45: 225-241.

Bushman, Robert and Williams, Christopher (2012) Accounting discretion, loan loss provisioning, and discipline of banks' risk taking, Journal of Accounting Economics, 54: 1-18.

Cameron, A. Colin and Trivedi, Pravin K. (2005) Microeconometrics: methods and applications. Cambridge University Press.

Cannata, Francesco, Casellina, Simone and Guidi, Gregorio (2012) Inside the labyrinth of Basel riskweighted assets: how not to get lost, Bank of Italy, occasional paper no. 132. 
Carboni, Marika, Fiordelisi, Franco, Ricci, Ornella and Lopes, Francesco Saverio Stentella (2017). Surprised or not surprised? The investors' reaction to the comprehensive assessment preceding the launch of the banking union. Journal of Banking \& Finance, 74, 122-132.

Cong, Ronna (2000) Marginal effects of the tobit model. Stata Technical Bulletin 56: 27-34.

Das, Sonali and Sy, Amadou (2012) How risky are banks' risk weighted assets? Evidence from the financial crisis, IMF working paper.

Demirgüç-Kunt, Asli, Detragiache, Enrica and Merrouche, Ouarda (2013) Bank capital: lesson from the financial crisis, Journal of Money Credit and Banking, 45: 1147-1163

Estrella, Arturo, Park, Sangkyun and Peristiani, Stavros (2002) Capital ratios and credit rating as predictors of bank failures, Federal Reserve Bank of New York Economic Policy Review, 6: 33-52.

European Banking Authority (2011) EBA recommendation on the creation and supervisory oversight of temporary capital buffers to restore market confidence, available on http://goo.gl/JiFoCT.

European Banking Authority (2013) Interim results update of the EBA review of the consistency of risk weighted assets, available on http://goo.gl/leNuwX.

European Banking Authority (2014) Guidelines on common procedures and methodologies for the supervisory review and evaluation process (SREP), EBA/GL/2014/13, available on https://goo.gl/YNTjJl.

European Central Bank (2014a), Aggregate report on the comprehensive assessment, available on http://goo.gl/qgnqWU.

European Central Bank (2014b) Institutions included in the comprehensive assessment, available on http://goo.gl/HV7UPo.

European Central Bank (2014c), Template for the Comprehensive Assessment Outcome, available on http://goo.gl/2KeaOY.

Federal Reserve (2015) Comprehensive Capital Analysis and Review 2015: Assessment Framework and Results. Federal Reserve, Washington DC. URL http://www.federalreserve.gov/newsevents/press/bcreg/bcreg20150311a1.pdf.

Fiordelisi, Franco, Ricci, Ornella and Lopes, Francesco Saverio Stentella (2017). The unintended consequences of the launch of the single supervisory mechanism in Europe. To Appear on Journal of Financial and Quantitative Analysis.

Greenlaw, David, Kashyap, Anil K., Schoenholtz , Kermit L., and Shin, Hyun Song (2012) Stressed out: Macroprudential principles for stress testing. Chicago Booth Research Paper 12-08.

Haldane, Andrew (2011) Capital discipline, Bank of England, mimeo.

Haldane, Andrew (2012) The dog and the frisbee, Bank of England, mimeo. 
Huizinga, Harry and Laeven, Luc (2012) Bank valuation and accounting discretion during a financial crisis, Journal of Financial Economics, 106: 614-634.

Laeven, Luc, Ratnovski, Lev, and Tong, Hui (2014) Bank size and systemic risk. IMF Staff Discussion Note, 14/04.

Le Leslé, Vanessaand and Avramova, Sofiya (2012) Revisiting risk-weighted assets, IMF working paper, $12 / 90$.

Mariathasan, Mike and Merrouche, Ouarda (2012) Recapitalization, credit and liquidity, Economic Policy, 27: 603-646.

Mariathasan, Mike and Merrouche, Ourada (2014) The manipulation of Basel risk weights, Journal of Financial Intermediation, 23: 300-321.

Massaro, Fabrizio (2014) Dai derivati ai titoli di Stato, Corriere della Sera, October 29, 2014.

Reuters (2017) Italy has done too little on banks' soured loans-ECB's Nouy tells paper, available on https://goo.gl/4mG7ES.

Sahin, Cenkhan, and de Haan, Jakob (2016). Market reactions to the ECB's Comprehensive Assessment. Economics Letters, 140, 1-5.

Vallascas, Francesco and Hagendorff, Jens (2013) The risk sensitivity of capital requirements: evidence from an international sample of large banks, Review of Finance, 17: 1947-1988.

Visco, Ignazio (2014) L'attuazione dell'Unione bancaria europea e il credito all'economia, Audizione del Governatore della Banca d’Italia, Camera dei Deputati, dicembre 2014.

Wooldridge, Jeffrey M. (2002) Econometric analysis of cross section and panel data. Cambridge, MA: The MIT Press. 


\section{List of Abbreviations}

ADJ_AQR Adjustment due to the AQR

ADJ_ST Adjustment due to the ST adverse scenario

AQR Asset Quality Review

bps basis points ( $1 \mathrm{bp}$ is equal to $0.01 \%$ )

bn billion

CA Comprehensive Assessment

CET1 Common Equity Tier 1

CR Coverage Ratio

CRD/CRR Capital Requirements Directive/Capital Requirements Regulation

CVA Credit Valuation Adjustment

EBA European Banking Authority

ECB European Central Bank

LM test Lagrange-Multiplier test

NPE Non Performing Exposure

RWA Risk Weighted Asset

SF_AQR Shortfall due to the AQR

SF_ST Shortfall due to the ST adverse scenario

SREP Supervisory Review and Evaluation Process

SSM Single Supervisory Mechanism

ST Stress Test

$\operatorname{tr} \quad$ trillion (one thousand of billions)

\section{Figures and Tables}

Figure 1. Relationship between non-performing exposures ratio (non performing loans over total loans) and CET1 ratio

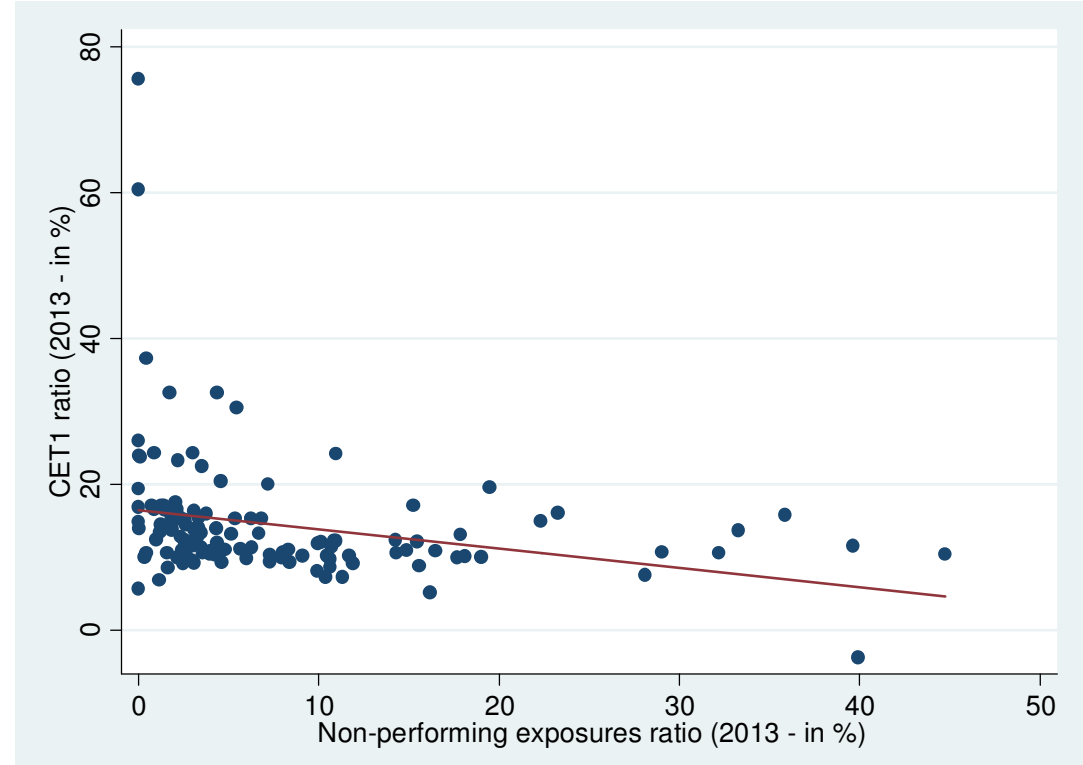

Source: our elaborations on EBA and ECB data. 
Figure 2. Relationship between CET1 ratio and comprehensive assessment shortfalls

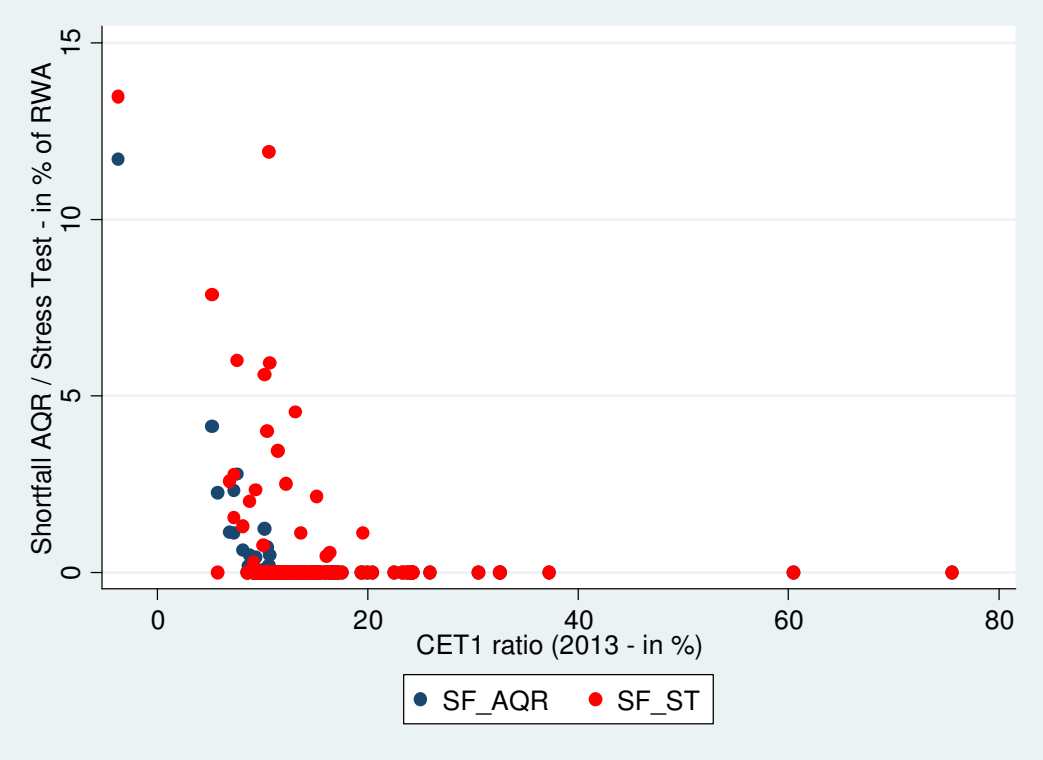

Source: our elaborations on EBA and ECB data.

Table 1 - Sample by country

\begin{tabular}{|l|c|c|}
\hline \multirow{2}{*}{} & \multicolumn{2}{|c|}{ Number of banks } \\
\cline { 2 - 3 } & ECB data & EBA data \\
\hline Austria & 6 & 6 \\
\hline Belgium & 6 & 5 \\
\hline Cyprus & 4 & 3 \\
\hline Estonia & 3 & 0 \\
\hline Finland & 3 & 1 \\
\hline France & 13 & 11 \\
\hline Germany & 25 & 24 \\
\hline Greece & 4 & 4 \\
\hline Ireland & 5 & 3 \\
\hline Italy & 15 & 15 \\
\hline Latvia & 3 & 1 \\
\hline Lithuania & 3 & 0 \\
\hline Luxembourg & 6 & 2 \\
\hline Malta & 2 & 1 \\
\hline Netherlands & 7 & 6 \\
\hline Portugal & 3 & 3 \\
\hline Slovakia & 3 & 0 \\
\hline Slovenia & 3 & 3 \\
\hline Spain & 15 & 15 \\
\hline \hline Total & 129 & 103 \\
\hline Source:Authors & & \\
\hline
\end{tabular}

Source: Authors' computations 
Table 2 - Summary statistics and definitions of variables

\begin{tabular}{|c|c|c|c|c|c|c|c|}
\hline Variable & Description & Source & Mean & SD & Min & Max & Obs \\
\hline ADJ_AQR & $\begin{array}{l}\text { Adjustments due to the AQR exercise } \\
\text { over RWA (in \%) }\end{array}$ & ECB & 0.833 & 1.130 & 0.000 & 5.800 & 129 \\
\hline ADJ_ST & $\begin{array}{l}\text { Adjustments due to the Adverse } \\
\text { Scenario over RWA (in \%) }\end{array}$ & $\mathrm{ECB}$ and $\mathrm{EBA}$ & 8.090 & 8.330 & -9.460 & 65.000 & 103 \\
\hline cet1 & Common Equity Tier 1 ratio (in \%) & ECB & 14.500 & 8.790 & -3.700 & 75.600 & 129 \\
\hline $\mathrm{cr}$ & $\begin{array}{l}\text { Coverage ratio for non-performing } \\
\text { exposure (in \%) }\end{array}$ & ECB & 42.000 & 17.700 & 0.000 & 99.800 & 129 \\
\hline Dcore & $\begin{array}{l}\text { Dummy equal to } 1 \text { for banks operating } \\
\text { in Austria, Belgium, Germany, Finland, } \\
\text { France, Luxembourg and the } \\
\text { Netherlands (euro area core } \\
\text { countries); } 0 \text { otherwise }\end{array}$ & $\begin{array}{l}\text { Own } \\
\text { elaboration }\end{array}$ & 0.512 & 0.502 & 0.000 & 1.000 & 129 \\
\hline Dirb & $\begin{array}{l}\text { Dummy equal to } 1 \text { for banks with a } \\
\text { credit risk exposure, not adjusted for } \\
\text { risk, under IRB models (F-IRB and A- } \\
\text { IRB) with over } 50 \% \text { of total credit risk } \\
\text { exposure; } 0 \text { otherwise }\end{array}$ & ECB and EBA & 0.465 & 0.501 & 0.000 & 1.000 & 129 \\
\hline Dmediumsize & $\begin{array}{l}\text { Dummy equal to } 1 \text { for banks with total } \\
\text { assets in the second and third quartile } \\
\text { of the distribution; } 0 \text { otherwise }\end{array}$ & ECB & 0.496 & 0.502 & 0.000 & 1.000 & 129 \\
\hline Dlargesize & $\begin{array}{l}\text { Dummy equal to } 1 \text { for banks with total } \\
\text { assets in the fourth quartile of the } \\
\text { distribution; } 0 \text { otherwise }\end{array}$ & ECB & 0.256 & 0.438 & 0.000 & 1.000 & 129 \\
\hline Drestruct & $\begin{array}{l}\text { Dummy equal to } 1 \text { for banks with } \\
\text { restructuring plans approved before } 31 \\
\text { December } 2013 \text { (dynamic balance } \\
\text { sheet assumption); } 0 \text { otherwise }\end{array}$ & ECB & 0.186 & 0.391 & 0.000 & 1.000 & 129 \\
\hline homebias & $\begin{array}{l}\text { Credit risk exposure, not adjusted for } \\
\text { risk, and government bond gross direct } \\
\text { exposure over home domestic country } \\
\text { total assets (in \%) }\end{array}$ & EBA & 81.600 & 28.600 & 1.930 & 135.000 & 103 \\
\hline level3 & $\begin{array}{l}\text { Level } 3 \text { instruments for total assets (in } \\
\%)\end{array}$ & ECB & 0.789 & 1.530 & 0.000 & 10.000 & 129 \\
\hline loan & $\begin{array}{l}\text { Total gross loans over total assets in } \\
2013 \text { (in \%) }\end{array}$ & Bankscope & 57.200 & 20.600 & 0.786 & 97.500 & 118 \\
\hline Ir & $\begin{array}{l}\text { Leverage ratio (common equity tier } 1 \\
\text { divided by total exposure measure } \\
\text { according to Article } 429 \text { CRR) (in \%) }\end{array}$ & ECB & 5.950 & 3.340 & 0.590 & 21.400 & 129 \\
\hline marketcap & $\begin{array}{l}\text { Stock exchange market capitalization } \\
\text { over nominal GDP (in \%) }\end{array}$ & World Bank & 48.300 & 29.700 & 3.930 & 128.000 & 129 \\
\hline npe & Non-performing exposure ratio (in \%) & ECB & 7.580 & 9.010 & 0.000 & 44.700 & 129 \\
\hline rwa & $\begin{array}{l}\text { Total risk exposure (RWA) over total } \\
\text { assets (in \%) }\end{array}$ & ECB & 45.400 & 20.000 & 0.143 & 110.000 & 129 \\
\hline SF_AQR & $\begin{array}{l}\text { Capital shortfall to threshold of } 8 \% \text { for } \\
\text { AQR adjusted CET1 ratio (bn EUR) }\end{array}$ & ECB & 0.041 & 0.166 & 0.000 & 1.030 & 129 \\
\hline SF_ST & $\begin{array}{l}\text { Capital shortfall to threshold of 5.5\% } \\
\text { in Adverse Scenario (bn EUR) }\end{array}$ & ECB & 0.188 & 0.671 & 0.000 & 4.630 & 129 \\
\hline sys & Total assets over nominal GDP (in \%) & $\begin{array}{l}\text { ECB and } \\
\text { World Bank }\end{array}$ & 28.600 & 35.900 & 0.491 & 180.000 & 129 \\
\hline
\end{tabular}

Notes: All data, with the exceptions of capital shortfalls, adjustments and post-AQR variables, refer to 2013.The Dexia Ir variable is equal to CET1 capital over total assets due to missing data for the total exposure measured according to Article 429 CRR. 
Table 3 - Summary statistics by country. Average values

\begin{tabular}{|l|c|c|c|c|c|c|c|c|c|c|}
\hline & $\mathrm{AT}$ & $\mathrm{BE}$ & $\mathrm{CY}$ & $\mathrm{DE}$ & $\mathrm{EE}$ & $\mathrm{ES}$ & $\mathrm{FI}$ & $\mathrm{FR}$ & $\mathrm{GR}$ & $\mathrm{IE}$ \\
\hline ADJ_AQR & 0.964 & 0.433 & 1.470 & 0.437 & 2.370 & 0.365 & 0.627 & 0.226 & 3.610 & 0.323 \\
\hline ADJ_ST & 6.990 & 7.930 & -4.190 & 9.890 & - & 8.520 & 12.200 & 11.900 & -1.570 & 5.170 \\
\hline cet1 & 12.700 & 16.300 & 7.750 & 13.400 & 25.300 & 10.700 & 15.500 & 17.400 & 12.700 & 13.400 \\
\hline cr & 50.200 & 34.200 & 36.600 & 36.700 & 35.900 & 50.900 & 38.000 & 47.000 & 44.200 & 48.900 \\
\hline Dirb & 0.167 & 0.833 & 0.000 & 0.640 & 0.667 & 0.067 & 0.333 & 0.692 & 0.000 & 0.800 \\
\hline Drestruct & 0.167 & 0.500 & 0.250 & 0.160 & 0.000 & 0.600 & 0.000 & 0.077 & 0.000 & 0.200 \\
\hline homebias & 69.600 & 51.400 & 88.600 & 77.900 & - & 84.600 & 94.100 & 75.800 & 82.200 & 89.200 \\
\hline lasset & 4.090 & 4.520 & 2.530 & 4.510 & 1.020 & 4.730 & 4.500 & 5.380 & 4.460 & 4.490 \\
\hline level3 & 0.953 & 1.470 & 0.185 & 0.657 & 0.001 & 0.333 & 0.416 & 0.927 & 0.202 & 0.184 \\
\hline loan & 51.800 & 41.900 & 80.700 & 46.300 & 78.100 & 64.000 & 59.700 & 51.200 & 76.400 & 76.400 \\
\hline Ir & 6.380 & 2.790 & 6.590 & 4.620 & 16.200 & 5.170 & 5.980 & 5.340 & 7.470 & 7.460 \\
\hline marketcap & 26.900 & 62.100 & 8.770 & 43.400 & 10.400 & 75.200 & 64.200 & 69.800 & 18.000 & 51.800 \\
\hline npe & 5.770 & 2.190 & 28.700 & 2.770 & 3.700 & 9.080 & 1.500 & 2.570 & 32.600 & 19.300 \\
\hline rwa & 57.100 & 24.200 & 56.000 & 37.100 & 73.700 & 47.800 & 40.500 & 37.100 & 59.200 & 53.200 \\
\hline SF_AQR & 0.000 & 0.000 & 0.327 & 0.004 & 0.000 & 0.002 & 0.000 & 0.010 & 0.086 & 0.000 \\
\hline SF_ST & 0.144 & 0.090 & 0.591 & 0.009 & 0.000 & 0.000 & 0.000 & 0.000 & 2.180 & 0.171 \\
\hline sys & 26.000 & 32.700 & 91.600 & 6.680 & 24.600 & 20.300 & 72.400 & 25.100 & 48.300 & 73.800 \\
\hline
\end{tabular}

\begin{tabular}{|l|c|c|c|c|c|c|c|c|c|}
\hline & $\mathrm{IT}$ & $\mathrm{LT}$ & $\mathrm{LU}$ & $\mathrm{LV}$ & $\mathrm{MT}$ & $\mathrm{NL}$ & $\mathrm{PT}$ & $\mathrm{SI}$ & $\mathrm{SK}$ \\
\hline ADJ_AQR & 1.500 & 0.454 & 0.188 & 1.050 & 0.756 & 0.980 & 1.100 & 2.300 & 0.684 \\
\hline ADJ_ST & 3.750 & - & 11.700 & 7.100 & 8.550 & 19.300 & 6.080 & 5.740 & - \\
\hline cet1 & 9.380 & 18.300 & 19.200 & 19.400 & 10.600 & 23.500 & 12.800 & 20.000 & 17.300 \\
\hline cr & 37.700 & 40.900 & 33.300 & 50.300 & 37.600 & 37.400 & 30.600 & 65.200 & 58.500 \\
\hline Dirb & 0.333 & 0.667 & 0.500 & 0.667 & 0.000 & 0.714 & 0.333 & 0.000 & 1.000 \\
\hline Drestruct & 0.067 & 0.000 & 0.000 & 0.000 & 0.000 & 0.143 & 0.667 & 0.000 & 0.000 \\
\hline homebias & 103.000 & - & 49.000 & 39.800 & 100.000 & 78.600 & 87.600 & 93.900 & - \\
\hline lasset & 4.360 & 1.630 & 2.980 & 1.420 & 1.820 & 5.200 & 4.240 & 1.820 & 2.380 \\
\hline level3 & 0.708 & 0.163 & 0.558 & 4.780 & 0.000 & 0.403 & 4.330 & 1.690 & 0.139 \\
\hline loan & 65.200 & 68.300 & 17.200 & 53.600 & 55.500 & 70.700 & 67.400 & 50.200 & 67.400 \\
\hline Ir & 5.080 & 11.100 & 6.680 & 10.600 & 5.270 & 3.750 & 6.730 & 8.570 & 7.390 \\
\hline marketcap & 23.900 & 9.360 & 128.000 & 3.930 & 41.000 & 84.500 & 30.900 & 14.300 & 5.050 \\
\hline npe & 11.000 & 8.520 & 0.648 & 4.550 & 5.260 & 1.770 & 12.700 & 17.900 & 3.900 \\
\hline rwa & 58.600 & 64.600 & 27.500 & 56.300 & 52.100 & 25.700 & 57.600 & 51.200 & 52.600 \\
\hline SF_AQR & 0.229 & 0.000 & 0.000 & 0.000 & 0.000 & 0.000 & 0.000 & 0.000 & 0.000 \\
\hline SF_ST & 0.628 & 0.000 & 0.000 & 0.000 & 0.000 & 0.000 & 0.379 & 0.022 & 0.000 \\
\hline sys & 9.730 & 15.400 & 50.800 & 18.000 & 86.900 & 51.100 & 45.000 & 20.100 & 15.100 \\
\hline
\end{tabular}

Note: All data, with the exception of capital shortfalls and adjustments, refer to 2013. 
Table 4 - Correlation matrix

\begin{tabular}{|l|c|c|c|c|c|c|c|}
\hline & cet1 & cr & Dcore & Dirb & Dmediumsize & Dlargesize & Drestruct \\
\hline cet1 & 1.00 & & & & & & \\
\hline cr & -0.27 & 1.00 & & & & & \\
\hline Dcore & -0.18 & 0.15 & 1.00 & & & & \\
\hline Dirb & 0.02 & 0.07 & -0.29 & 1.00 & & & \\
\hline Dmediumsize & -0.08 & 0.17 & -0.25 & 0.31 & 1.00 & & \\
\hline Dlargesize & -0.01 & -0.21 & 0.02 & -0.18 & -0.58 & 1.00 & \\
\hline Drestruct & -0.12 & -0.02 & 0.09 & 0.07 & 0.18 & 0.08 & 1.00 \\
\hline homebias & 0.11 & -0.14 & 0.30 & -0.33 & -0.31 & 0.25 & -0.05 \\
\hline level3 & 0.00 & 0.00 & 0.02 & -0.02 & -0.01 & 0.04 & 0.03 \\
\hline loan & -0.04 & -0.01 & 0.39 & -0.18 & -0.20 & 0.21 & 0.00 \\
\hline Ir & 0.23 & 0.23 & 0.31 & -0.06 & -0.31 & -0.07 & -0.21 \\
\hline marketcap & 0.13 & -0.05 & -0.47 & 0.07 & 0.20 & 0.11 & 0.14 \\
\hline npe & -0.27 & 0.10 & 0.57 & -0.20 & -0.19 & 0.18 & 0.10 \\
\hline rwa & -0.30 & 0.38 & 0.49 & -0.17 & -0.27 & 0.02 & -0.09 \\
\hline sys & -0.09 & 0.08 & 0.07 & 0.05 & 0.37 & -0.25 & 0.02 \\
\hline
\end{tabular}

\begin{tabular}{|l|c|c|c|c|c|c|c|}
\cline { 2 - 8 } \multicolumn{1}{c|}{} & homebias & level3 & loan & Ir & marketcap & npe & rwa \\
\hline home_bias & 1.00 & & & & & & \\
\hline level3 & -0.08 & 1.00 & & & & & \\
\hline Ioan & 0.29 & -0.11 & 1.00 & & & & \\
\hline Ir & 0.23 & 0.11 & 0.27 & 1.00 & & & \\
\hline marketcap & -0.20 & -0.12 & -0.10 & -0.29 & 1.00 & & \\
\hline npe & 0.18 & -0.01 & 0.49 & 0.20 & -0.38 & 1.00 & \\
\hline rwa & 0.16 & 0.09 & 0.44 & 0.61 & -0.45 & 0.50 & 1.00 \\
\hline sys & -0.36 & -0.01 & 0.10 & 0.01 & 0.13 & 0.22 & -0.08 \\
\hline
\end{tabular}

Observations equal to 129 , with the exception of homebias, for which there are 100 observations, and for loan (93 obs). 
Table 5. Regression results - reference model for capital shortfall (Tobit estimator)

\begin{tabular}{|c|c|c|c|c|c|c|}
\hline Model & I & II & III & IV & V & VI \\
\hline Dependent var. & SF_AQR & SF_AQR & SF_AQR & SF_ST & SF_ST & SF_ST \\
\hline \multirow[t]{2}{*}{ cet1 } & $-0.104 * * *$ & - & $-0.103 * * *$ & $-0.080 *$ & - & -0.004 \\
\hline & [0.014] & & [0.013] & [0.046] & & {$[0.034]$} \\
\hline \multirow[t]{2}{*}{ Ir } & - & $-0.175 * * *$ & -0.062 & - & $-0.606 * * *$ & $-0.604 * * *$ \\
\hline & & [0.051] & [0.040] & & [0.143] & [0.145] \\
\hline \multirow[t]{2}{*}{ Dmediumsize } & $0.608 * * *$ & 0.124 & $0.499 * * *$ & $1.334^{* *}$ & $0.847^{* *}$ & $0.849 * *$ \\
\hline & [0.156] & [0.198] & [0.164] & [0.513] & [0.383] & [0.383] \\
\hline \multirow[t]{2}{*}{ Dlargesize } & $0.870 * * *$ & 0.300 & $0.780 * * *$ & $1.518^{*}$ & 0.666 & 0.658 \\
\hline & [0.269] & [0.298] & [0.269] & [0.869] & [0.609] & [0.617] \\
\hline \multirow[t]{2}{*}{ npe } & $0.037 * * *$ & $0.054 * * *$ & $0.035 * * *$ & $0.107^{* * *}$ & $0.159 * * *$ & $0.159 * * *$ \\
\hline & [0.010] & [0.015] & [0.010] & [0.038] & [0.031] & {$[0.032]$} \\
\hline \multirow[t]{2}{*}{$\mathrm{cr}$} & $-0.020 * * *$ & $-0.020 * * *$ & $-0.014 * *$ & -0.012 & 0.009 & 0.010 \\
\hline & {$[0.006]$} & [0.007] & [0.006] & [0.013] & [0.011] & [0.011] \\
\hline \multirow[t]{2}{*}{ sys } & $-0.012 * * *$ & $-0.012 * * *$ & $-0.010 * * *$ & $-0.021 * *$ & $-0.024 * * *$ & $-0.024 * * *$ \\
\hline & [0.003] & [0.003] & [0.003] & [0.010] & [0.008] & [0.008] \\
\hline \multirow[t]{2}{*}{ marketcap } & $-0.016^{* * *}$ & $-0.022 * * *$ & $-0.017 * * *$ & $-0.044^{* * *}$ & $-0.057 * * *$ & $-0.057 * * *$ \\
\hline & [0.004] & [0.006] & [0.003] & [0.016] & [0.014] & [0.014] \\
\hline \multirow[t]{2}{*}{ level3 } & $-0.115^{*}$ & -0.085 & -0.055 & 0.059 & -0.004 & -0.003 \\
\hline & [0.063] & {$[0.057]$} & [0.068] & [0.126] & [0.109] & [0.113] \\
\hline \multirow[t]{2}{*}{ Drestruct } & $0.586 * * *$ & $0.531^{* * *}$ & $0.550 * * *$ & $0.936^{*}$ & $1.102 * *$ & $1.107^{* *}$ \\
\hline & {$[0.214]$} & [0.201] & {$[0.180]$} & [0.552] & {$[0.496]$} & {$[0.505]$} \\
\hline \multirow[t]{2}{*}{ Dirb } & $-0.246 * * *$ & $-0.475^{* * *}$ & $-0.278 * * *$ & 0.235 & 0.019 & 0.031 \\
\hline & {$[0.056]$} & {$[0.175]$} & {$[0.072]$} & {$[0.457]$} & {$[0.456]$} & {$[0.478]$} \\
\hline \multirow[t]{2}{*}{ constant } & $1.333 * * *$ & $1.546 * * *$ & $1.509 * * *$ & -0.181 & $1.907^{* *}$ & $1.920 * *$ \\
\hline & [0.240] & {$[0.431]$} & [0.249] & [1.020] & {$[0.746]$} & {$[0.766]$} \\
\hline \multirow[t]{2}{*}{ sigma } & $0.167 * * *$ & $0.361^{* * *}$ & $0.164 * * *$ & $1.317 * * *$ & $0.977 * * *$ & $0.977 * * *$ \\
\hline & {$[0.024]$} & [0.055] & {$[0.024]$} & {$[0.234]$} & [0.124] & [0.124] \\
\hline \multicolumn{7}{|l|}{ Collinearity diagnostics } \\
\hline VIF (mean) & 1.4 & 1.5 & 1.5 & 1.4 & 1.5 & 1.5 \\
\hline Condition index & 13.1 & 12.1 & 14.0 & 13.1 & 12.1 & 14.0 \\
\hline \multirow[t]{2}{*}{ LM test of Tobit specification } & 0.126 & 10.735 & 0.276 & 11.462 & 6.473 & 7.081 \\
\hline & {$[10.2 ; 13.4]$} & {$[9.9 ; 13.7]$} & {$[11.1 ; 14.3]$} & {$[8.1 ; 12.0]$} & {$[8.0 ; 11.8]$} & {$[7.4 ; 10.9]$} \\
\hline Log-likelihood value & 0.684 & -15.165 & 1.650 & -56.667 & -44.925 & -44.921 \\
\hline Pseudo R-squared & - & 0.679 & - & 0.344 & 0.480 & 0.480 \\
\hline F statistic ( $p$-value) & 0.000 & 0.000 & 0.000 & 0.016 & 0.000 & 0.000 \\
\hline Uncens. obs & 16 & 16 & 16 & 23 & 23 & 23 \\
\hline Obs & 129 & 129 & 129 & 129 & 129 & 129 \\
\hline
\end{tabular}

Notes: Cluster-robust standard errors appear in parentheses. 10\% and 5\% critical values for the LM test in parentheses. Pseudo R-squared is not reported for models I and III because is higher than 1 due to the positive value of log-likelihood in the full model and the negative value in the constant-only model. We use Stata13 for all calculations.

$*, * *, * * *$ indicate statistical significance of the parameters at the $10 \%, 5 \%$ and $1 \%$ significance levels respectively. 
Table 6. Regression results - Risk composition and capital shortfall (Tobit estimator)

\begin{tabular}{|c|c|c|c|c|c|c|}
\hline Model & I & II & III & IV & V & $\mathrm{VI}$ \\
\hline Dependent var. & SF_AQR & SF_AQR & SF_AQR & SF_ST & SF_ST & SF_ST \\
\hline cet1 & $\begin{array}{c}-0.101^{* * *} \\
{[0.010]}\end{array}$ & $\begin{array}{c}-0.094 * * * \\
{[0.014]}\end{array}$ & $\begin{array}{c}-0.103^{* * *} \\
{[0.013]}\end{array}$ & $\begin{array}{c}0.003 \\
{[0.035]}\end{array}$ & $\begin{array}{c}0.012 \\
{[0.044]}\end{array}$ & $\begin{array}{l}-0.005 \\
{[0.037]}\end{array}$ \\
\hline Ir & $\begin{array}{c}-0.096 * * \\
{[0.040]}\end{array}$ & $\begin{array}{l}-0.142 * \\
{[0.072]}\end{array}$ & $\begin{array}{l}-0.061 \\
{[0.042]}\end{array}$ & $\begin{array}{c}-0.644 * * * \\
{[0.168]}\end{array}$ & $\begin{array}{c}-0.660 * * * \\
{[0.158]}\end{array}$ & $\begin{array}{c}-0.576 * * * \\
{[0.157]}\end{array}$ \\
\hline Dmediumsize & $\begin{array}{c}0.476 * * * \\
{[0.156]}\end{array}$ & $\begin{array}{l}0.425 * * \\
{[0.186]}\end{array}$ & $\begin{array}{c}0.499 * * * \\
{[0.165]}\end{array}$ & $\begin{array}{c}0.766^{*} \\
{[0.436]}\end{array}$ & $\begin{array}{l}1.007^{* *} \\
{[0.418]}\end{array}$ & $\begin{array}{c}0.800 * \\
{[0.423]}\end{array}$ \\
\hline Dlargesize & $\begin{array}{c}0.806 * * * \\
{[0.252]}\end{array}$ & $\begin{array}{l}0.640 * * \\
{[0.302]}\end{array}$ & $\begin{array}{c}0.777^{* * *} \\
{[0.295]}\end{array}$ & $\begin{array}{c}0.563 \\
{[0.654]}\end{array}$ & $\begin{array}{c}1.073^{*} \\
{[0.631]}\end{array}$ & $\begin{array}{c}0.537 \\
{[0.700]}\end{array}$ \\
\hline npe & $\begin{array}{c}0.040 * * * \\
{[0.012]}\end{array}$ & $\begin{array}{c}0.026^{*} \\
{[0.015]}\end{array}$ & $\begin{array}{c}0.035^{* * *} \\
{[0.010]}\end{array}$ & $\begin{array}{c}0.158 * * * \\
{[0.033]}\end{array}$ & $\begin{array}{c}0.143 * * * \\
{[0.031]}\end{array}$ & $\begin{array}{c}0.158 * * * \\
{[0.035]}\end{array}$ \\
\hline $\mathrm{cr}$ & $\begin{array}{c}-0.017^{* *} \\
{[0.007]}\end{array}$ & $\begin{array}{l}-0.009 \\
{[0.013]}\end{array}$ & $\begin{array}{c}-0.014^{* *} \\
{[0.006]}\end{array}$ & $\begin{array}{c}0.009 \\
{[0.011]}\end{array}$ & $\begin{array}{c}0.016 \\
{[0.016]}\end{array}$ & $\begin{array}{c}0.011 \\
{[0.012]}\end{array}$ \\
\hline sys & $\begin{array}{c}-0.010 * * * \\
{[0.003]}\end{array}$ & $\begin{array}{c}-0.009 * * \\
{[0.004]}\end{array}$ & $\begin{array}{c}-0.010 * * * \\
{[0.003]}\end{array}$ & $\begin{array}{c}-0.023 * * * \\
{[0.008]}\end{array}$ & $\begin{array}{c}-0.031 * * * \\
{[0.006]}\end{array}$ & $\begin{array}{c}-0.025^{* * *} \\
{[0.008]}\end{array}$ \\
\hline marketcap & $\begin{array}{c}-0.012 * * * \\
{[0.003]}\end{array}$ & $\begin{array}{c}-0.022 * * * \\
{[0.005]}\end{array}$ & $\begin{array}{c}-0.017^{* * *} \\
{[0.003]}\end{array}$ & $\begin{array}{c}-0.055^{* * *} \\
{[0.014]}\end{array}$ & $\begin{array}{c}-0.074 * * * \\
{[0.014]}\end{array}$ & $\begin{array}{c}-0.057^{* * *} \\
{[0.015]}\end{array}$ \\
\hline level3 & $\begin{array}{l}-0.085 \\
{[0.063]}\end{array}$ & $\begin{array}{l}-0.050 \\
{[0.098]}\end{array}$ & $\begin{array}{l}-0.056 \\
{[0.069]}\end{array}$ & $\begin{array}{l}-0.017 \\
{[0.112]}\end{array}$ & $\begin{array}{c}0.035 \\
{[0.106]}\end{array}$ & $\begin{array}{l}-0.033 \\
{[0.136]}\end{array}$ \\
\hline Drestruct & $\begin{array}{c}0.500 * * * \\
{[0.183]}\end{array}$ & $\begin{array}{c}0.717^{* * *} \\
{[0.230]}\end{array}$ & $\begin{array}{c}0.550 * * * \\
{[0.183]}\end{array}$ & $\begin{array}{l}1.087 * * \\
{[0.514]}\end{array}$ & $\begin{array}{l}1.926 * * * \\
{[0.550]}\end{array}$ & $\begin{array}{l}1.082 * * \\
{[0.520]}\end{array}$ \\
\hline Dirb & $\begin{array}{l}-0.159 * \\
{[0.094]}\end{array}$ & $\begin{array}{c}-0.422 * * * \\
{[0.092]}\end{array}$ & $\begin{array}{l}-0.277 * * * \\
{[0.079]}\end{array}$ & $\begin{array}{c}0.081 \\
{[0.479]}\end{array}$ & $\begin{array}{l}-0.412 \\
{[0.509]}\end{array}$ & $\begin{array}{c}0.143 \\
{[0.553]}\end{array}$ \\
\hline rwa & $\begin{array}{l}0.009 * * * \\
{[0.003]}\end{array}$ & - & - & $\begin{array}{c}0.006 \\
{[0.014]}\end{array}$ & - & - \\
\hline Ioan & - & $\begin{array}{l}0.011 * * \\
{[0.005]}\end{array}$ & - & - & $\begin{array}{l}0.040 * * * \\
{[0.014]}\end{array}$ & - \\
\hline homebias & - & - & $\begin{array}{c}0.000 \\
{[0.002]}\end{array}$ & - & - & $\begin{array}{l}-0.003 \\
{[0.007]}\end{array}$ \\
\hline constant & $\begin{array}{l}1.110 * * * \\
{[0.165]}\end{array}$ & $\begin{array}{l}1.218 * * * \\
{[0.376]}\end{array}$ & $\begin{array}{l}1.495^{* * *} \\
{[0.413]} \\
\end{array}$ & $\begin{array}{l}1.742 * * \\
{[0.866]}\end{array}$ & $\begin{array}{l}-0.254 \\
{[1.228]}\end{array}$ & $\begin{array}{r}2.107^{*} \\
{[1.234]} \\
\end{array}$ \\
\hline sigma & $\begin{array}{l}0.153 * * * \\
{[0.024]}\end{array}$ & $\begin{array}{l}0.157^{* * *} \\
{[0.026]}\end{array}$ & $\begin{array}{l}0.164 * * * \\
{[0.023]}\end{array}$ & $\begin{array}{l}0.982 * * * \\
{[0.125]}\end{array}$ & $\begin{array}{l}0.911^{* * *} \\
{[0.119]}\end{array}$ & $\begin{array}{c}0.979 * * * \\
{[0.125]}\end{array}$ \\
\hline Collinearity diagnostics & & & & & & \\
\hline VIF (mean) & 1.8 & 0.7 & 1.2 & 1.8 & 0.7 & 1.2 \\
\hline Condition index & 18.9 & 16.9 & 20.1 & 18.9 & 16.9 & 20.1 \\
\hline $\begin{array}{l}\text { LM test of Tobit specification } \\
\text { [critical values: } 10 \% ; 5 \% \text { ] }\end{array}$ & $\begin{array}{c}1.151 \\
{[14.5 ; 16.2]}\end{array}$ & $\begin{array}{c}0.501 \\
{[13.7 ; 16.8]}\end{array}$ & $\begin{array}{c}0.276 \\
{[12.6 ; 15.5]}\end{array}$ & $\begin{array}{c}8.048 \\
{[7.9 ; 12.8]}\end{array}$ & $\begin{array}{c}8.268 \\
{[9.2 ; 12.5]}\end{array}$ & $\begin{array}{c}7.138 \\
{[9.9 ; 13.2]}\end{array}$ \\
\hline Log-likelihood value & 3.664 & 3.185 & 1.650 & -44.843 & -37.331 & -44.269 \\
\hline Pseudo R-squared & - & - & - & 0.481 & 0.546 & 0.453 \\
\hline F statistic (p-value) & 0.000 & 0.000 & 0.000 & 0.000 & 0.000 & 0.000 \\
\hline Uncens. obs & 16 & 15 & 16 & 23 & 22 & 23 \\
\hline Obs & 129 & 118 & 103 & 129 & 118 & 103 \\
\hline
\end{tabular}

Notes: Cluster-robust standard errors appear in parentheses. 10\% and 5\% critical values for the LM test in parentheses. Pseudo R-squared is not reported for models I, II and III because is higher than 1 due to the positive value of loglikelihood in the full model and the negative value in the constant-only model. We use Stata13 for all calculations.

$*, * *, * * *$ indicate statistical significance of the parameters at the $10 \%, 5 \%$ and $1 \%$ significance levels respectively. 
Table 7- Regression results - Core vs non-core country and capital shortfall in the AQR The table reports the estimation results based on the Tobit estimator.

Dependent variable: SF_AQR

\begin{tabular}{|c|c|c|c|c|c|}
\hline Model & I & II & III & IV & V \\
\hline \multirow[t]{2}{*}{ cet1 } & $-0.095 * * *$ & - & $-0.098 * * *$ & $-0.102 * * *$ & $-0.102 * * *$ \\
\hline & [0.011] & & [0.017] & [0.013] & [0.014] \\
\hline \multirow[t]{2}{*}{ Ir } & -0.026 & -0.028 & - & -0.027 & -0.026 \\
\hline & [0.043] & [0.047] & & [0.047] & [0.046] \\
\hline \multirow[t]{2}{*}{ Dmediumsize } & $0.538 * * *$ & $0.495^{* * *}$ & $0.524 * * *$ & $0.496 * * *$ & $0.504^{* * *}$ \\
\hline & [0.143] & [0.154] & [0.149] & [0.155] & [0.155] \\
\hline \multirow[t]{2}{*}{ Dlargesize } & $0.920 * * *$ & $0.814 * * *$ & $0.843^{* * *}$ & $0.790 * * *$ & $0.780 * * *$ \\
\hline & [0.204] & [0.207] & [0.288] & [0.222] & [0.254] \\
\hline \multirow[t]{2}{*}{ npe } & $0.029 * * *$ & $0.023^{* * *}$ & $0.026 * * *$ & - & $0.023 * * *$ \\
\hline & [0.008] & [0.007] & [0.009] & & [0.008] \\
\hline \multirow[t]{2}{*}{$\mathrm{cr}$} & $-0.027 * * *$ & -0.013 & -0.021 & -0.012 & - \\
\hline & [0.007] & [0.010] & [0.016] & [0.011] & \\
\hline \multirow[t]{2}{*}{ sys } & $-0.010 * * *$ & $-0.010 * * *$ & $-0.010 * * *$ & $-0.010 * * *$ & $-0.010 * * *$ \\
\hline & [0.002] & [0.002] & {$[0.002]$} & {$[0.002]$} & {$[0.002]$} \\
\hline \multirow[t]{2}{*}{ marketcap } & $-0.015^{* * *}$ & $-0.019 * * *$ & $-0.017 * * *$ & $-0.019 * * *$ & $-0.019 * * *$ \\
\hline & [0.003] & [0.003] & [0.005] & [0.003] & [0.004] \\
\hline \multirow[t]{2}{*}{ level3 } & $-0.157 * *$ & -0.121 & $-0.145^{*}$ & -0.123 & $-0.130 *$ \\
\hline & [0.076] & [0.079] & [0.081] & [0.078] & [0.078] \\
\hline \multirow[t]{2}{*}{ Drestruct } & $0.537 * * *$ & $0.688^{* * *}$ & $0.596 * *$ & $0.689 * * *$ & $0.669 * * *$ \\
\hline & [0.150] & [0.154] & [0.233] & [0.171] & [0.209] \\
\hline \multirow[t]{2}{*}{ Dirb } & $-0.196 * *$ & $-0.213 * * *$ & $-0.179 *$ & $-0.196 * * *$ & $-0.177 * *$ \\
\hline & [0.090] & [0.068] & [0.103] & [0.074] & [0.086] \\
\hline \multirow[t]{2}{*}{ 1-Dcore } & $0.548 * *$ & -0.958 & 0.221 & -0.110 & -0.040 \\
\hline & [0.218] & [0.716] & [0.835] & [0.438] & [0.567] \\
\hline \multirow[t]{2}{*}{ cet $1 \times$ Dcore } & - & $-0.254^{* * *}$ & - & - & - \\
\hline & & [0.069] & & & \\
\hline \multirow[t]{2}{*}{ cet1×(1-Dcore) } & - & $-0.102 * * *$ & - & - & - \\
\hline & & [0.012] & & & \\
\hline \multirow[t]{2}{*}{ Ir×Dcore } & - & - & -0.112 & - & - \\
\hline & & & [0.208] & & \\
\hline \multirow[t]{2}{*}{ Ir×(1-Dcore) } & - & - & -0.025 & - & - \\
\hline & & & [0.045] & & \\
\hline \multirow[t]{2}{*}{ npexDcore } & - & - & - & $-0.176^{*}$ & - \\
\hline & & & & [0.103] & \\
\hline \multirow[t]{2}{*}{ npex(1-Dcore) } & - & - & - & $0.023^{* * *}$ & - \\
\hline & & & & [0.007] & \\
\hline \multirow[t]{2}{*}{ cr×Dcore } & - & - & - & - & $-0.034 * * *$ \\
\hline & & & & & [0.008] \\
\hline \multirow[t]{2}{*}{ cr×(1-Dcore) } & - & - & - & - & -0.014 \\
\hline & & & & & [0.013] \\
\hline constant & $1.272 * * *$ & $2.532 * * *$ & $1.496 * *$ & $1.677^{* * *}$ & $1.638 * * *$ \\
\hline
\end{tabular}




\begin{tabular}{|c|c|c|c|c|c|}
\hline sigma & $\begin{array}{c}{[0.226]} \\
0.135 * * * \\
{[0.021]} \\
\end{array}$ & $\begin{array}{c}{[0.617]} \\
0.130 * * * \\
{[0.020]}\end{array}$ & $\begin{array}{c}{[0.591]} \\
0.136 * * * \\
{[0.021]} \\
\end{array}$ & $\begin{array}{c}{[0.349]} \\
0.131^{* * *} \\
{[0.020]}\end{array}$ & $\begin{array}{c}{[0.417]} \\
0.134 * * * \\
{[0.020]}\end{array}$ \\
\hline \multicolumn{6}{|l|}{ Collinearity diagnostics } \\
\hline VIF (mean) & 1.2 & 1.6 & 1.7 & 1.4 & 1.9 \\
\hline Condition index & 15.1 & 17.2 & 15.6 & 15.8 & 19.7 \\
\hline LM test of Tobit specification & $\begin{array}{c}0.183 \\
{[11.1 ; 14.1]}\end{array}$ & $\begin{array}{c}0.079 \\
{[11.1 ; 16.4]}\end{array}$ & $\begin{array}{c}0.080 \\
{[11.0 ; 16.2]}\end{array}$ & $\begin{array}{c}0.047 \\
{[13.5 ; 15.9]}\end{array}$ & $\begin{array}{c}0.030 \\
{[11.5 ; 13.9]}\end{array}$ \\
\hline$\left.\frac{\partial \mathrm{SF}_{-} \mathrm{aqr}}{\partial Z_{\text {Door } \varepsilon}}\right|_{z}$ & - & $-3.124 * * *$ & -0.585 & $-0.703 *$ & $-1.432 * * *$ \\
\hline$\left.\frac{\partial S F_{\text {_aqr }}}{\left.\partial Z_{(1-D \text { ores }}\right|_{Z}}\right|_{z}$ & - & $-2.210 * * *$ & 0.088 & -0.018 & $-0.639 * * *$ \\
\hline Log-likelihood value & 5.011 & 6.396 & 5.090 & 6.065 & 5.548 \\
\hline F statistic ( $p$-value) & 0.000 & 0.000 & 0.000 & 0.000 & 0.000 \\
\hline Uncens. obs & 16 & 16 & 16 & 16 & 16 \\
\hline Obs & 129 & 129 & 129 & 129 & 129 \\
\hline
\end{tabular}

Notes: Cluster-robust standard errors appear in parentheses. 10\% and 5\% critical values for the LM test in parentheses. Pseudo R-squared is not reported because is higher than 1 due to the positive value of log-likelihood in the full model and the negative value in the constant-only model. We use Stata13 for all calculations. Derivatives are evaluated at the median value of the $Z$ control variable interacted with Dcore and (1-Dcore).

$*, * *, * * *$ indicate statistical significance of the parameters at the $10 \%, 5 \%$ and $1 \%$ significance levels respectively. 
Table 8- Regression results - Core vs non-core country and capital shortfall in the Stress Test The table reports the estimation results based on the Tobit estimator.

Dependent variable: SF_ST

\begin{tabular}{|c|c|c|c|c|c|}
\hline Model & 1 & II & III & IV & V \\
\hline \multirow[t]{2}{*}{ cet1 } & -0.004 & - & -0.022 & -0.013 & 0.002 \\
\hline & [0.035] & & [0.039] & [0.037] & [0.038] \\
\hline \multirow[t]{2}{*}{ Ir } & $-0.603 * * *$ & $-0.597 * * *$ & - & $-0.587 * * *$ & $-0.602 * * *$ \\
\hline & [0.145] & [0.144] & & [0.144] & [0.146] \\
\hline \multirow[t]{2}{*}{ Dmediumsize } & $0.848 * *$ & $0.870 * *$ & $1.015^{* *}$ & $0.923 * *$ & $0.787^{*}$ \\
\hline & [0.383] & [0.391] & [0.402] & [0.399] & [0.427] \\
\hline \multirow[t]{2}{*}{ Dlargesize } & 0.665 & 0.662 & 0.608 & 0.641 & 0.624 \\
\hline & [0.620] & [0.609] & [0.638] & [0.636] & [0.662] \\
\hline \multirow[t]{2}{*}{ npe } & $0.158 * * *$ & $0.156 * * *$ & $0.156^{* * *}$ & - & $0.160 * * *$ \\
\hline & [0.033] & [0.033] & [0.032] & & [0.033] \\
\hline \multirow[t]{2}{*}{$\mathrm{cr}$} & 0.009 & 0.011 & 0.016 & 0.011 & - \\
\hline & [0.011] & [0.013] & [0.013] & [0.011] & \\
\hline \multirow[t]{2}{*}{ sys } & $-0.024 * * *$ & $-0.024 * * *$ & $-0.027 * * *$ & $-0.026 * * *$ & $-0.024 * * *$ \\
\hline & [0.008] & [0.008] & [0.008] & [0.008] & [0.008] \\
\hline \multirow[t]{2}{*}{ marketcap } & $-0.056 * * *$ & $-0.057 * * *$ & $-0.065^{* * *}$ & $-0.059 * * *$ & $-0.055 * * *$ \\
\hline & [0.013] & [0.013] & [0.017] & [0.014] & [0.014] \\
\hline \multirow[t]{2}{*}{ level3 } & -0.003 & -0.002 & -0.033 & 0.036 & 0.000 \\
\hline & [0.113] & [0.110] & [0.109] & [0.102] & [0.113] \\
\hline \multirow[t]{2}{*}{ Drestruct } & $1.100 * *$ & $1.105^{* *}$ & $1.427^{* *}$ & $1.227^{* *}$ & $1.083 * *$ \\
\hline & [0.503] & [0.490] & [0.648] & [0.534] & [0.502] \\
\hline \multirow[t]{2}{*}{ Dirb } & 0.038 & 0.067 & 0.079 & 0.083 & 0.041 \\
\hline & [0.488] & [0.487] & [0.502] & [0.495] & [0.489] \\
\hline \multirow[t]{2}{*}{ 1-Dcore } & 0.052 & 0.402 & -1.159 & -0.399 & 0.389 \\
\hline & [0.466] & [0.858] & [1.205] & [0.544] & [1.277] \\
\hline \multirow[t]{2}{*}{ cet1×Dcore } & - & 0.014 & - & - & - \\
\hline & & [0.034] & & & \\
\hline \multirow[t]{2}{*}{ cet $1 \times(1$-Dcore $)$} & - & -0.016 & - & - & - \\
\hline & & [0.043] & & & \\
\hline \multirow[t]{2}{*}{ IrxDcore } & - & - & $-0.825 * * *$ & - & - \\
\hline & & & [0.246] & & \\
\hline \multirow[t]{2}{*}{ Irx(1-Dcore) } & - & - & $-0.543 * * *$ & - & - \\
\hline & & & [0.164] & & \\
\hline \multirow[t]{2}{*}{ npexDcore } & - & - & - & 0.088 & - \\
\hline & & & & [0.068] & \\
\hline \multirow[t]{2}{*}{ npex(1-Dcore) } & - & - & - & $0.165^{* * *}$ & - \\
\hline & & & & [0.033] & \\
\hline \multirow[t]{2}{*}{ cr×Dcore } & - & - & - & - & 0.012 \\
\hline & & & & & [0.016] \\
\hline \multirow[t]{2}{*}{ cr×(1-Dcore) } & - & - & - & - & 0.004 \\
\hline & & & & & [0.019] \\
\hline constant & $1.882 * *$ & 1.575 & $2.843^{* *}$ & $2.140 * *$ & 1.684 \\
\hline
\end{tabular}




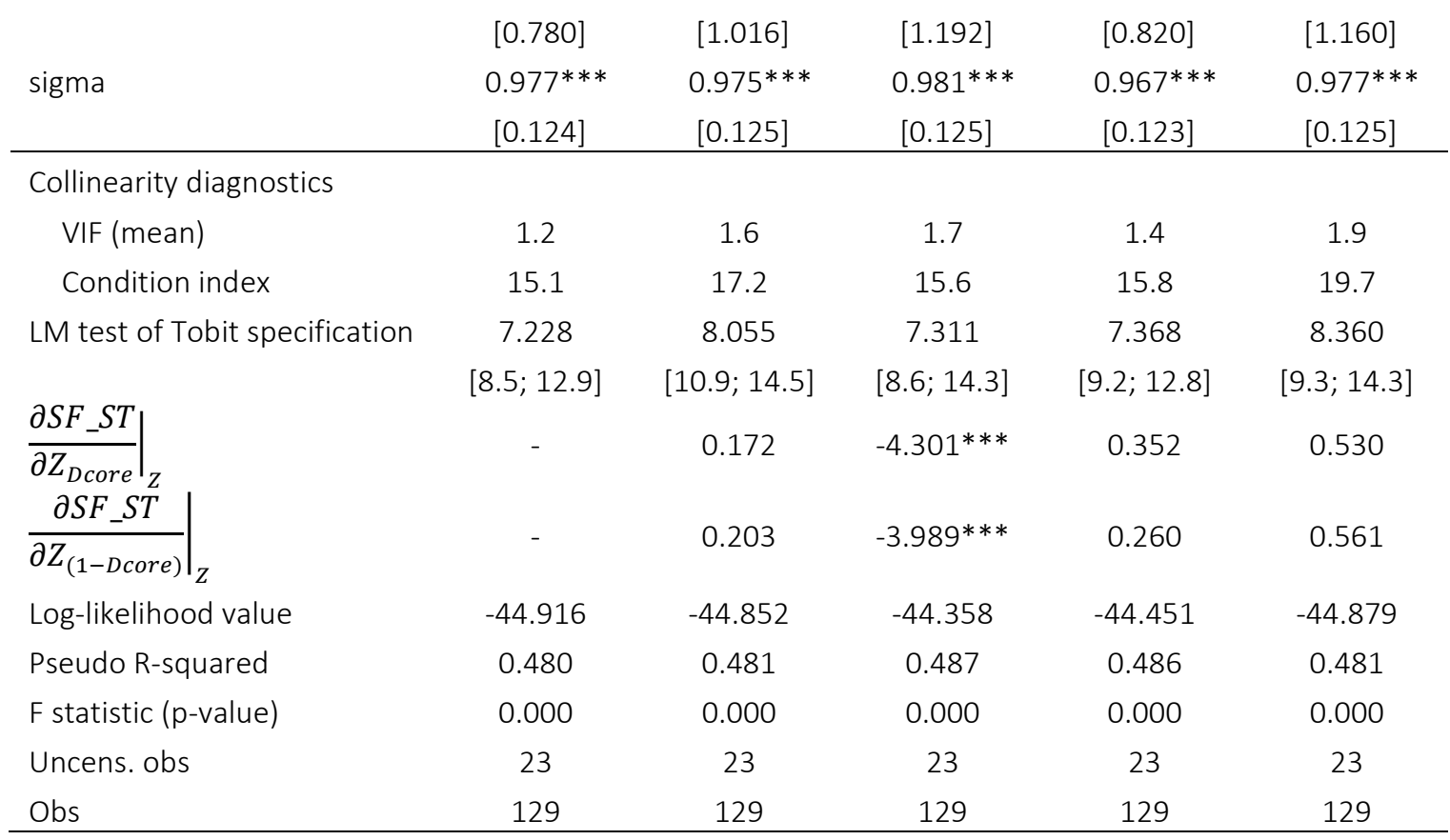

Notes: Cluster-robust standard errors appear in parentheses. $10 \%$ and 5\% critical values for the LM test in parentheses. We use Stata13 for all calculations. ${ }^{*}, * * * *$ indicate statistical significance of the parameters at the 10\%, 5\% and $1 \%$ significance levels respectively. Derivatives are evaluated at the median value of the $Z$ control variable interacted with Dcore and (1-Dcore). 
Table 9. Regression results - Adjustments

The table reports the estimation results based on the OLS estimator.

\begin{tabular}{|c|c|c|c|c|}
\hline Model & I & $\|$ & III & IV \\
\hline Dependent var. & ADJ_AQR & ADJ_AQR & ADJ_ST & ADJ_ST \\
\hline \multirow[t]{2}{*}{ cet1 } & $0.024 *$ & 0.023 & $0.791 * * *$ & $0.801 * * *$ \\
\hline & {$[0.014]$} & [0.016] & [0.056] & [0.059] \\
\hline \multirow[t]{2}{*}{ Ir } & -0.025 & -0.023 & $0.596 * * *$ & $0.538 * * *$ \\
\hline & [0.052] & {$[0.054]$} & [0.145] & [0.201] \\
\hline \multirow[t]{2}{*}{ Dmediumsize } & 0.036 & 0.036 & 0.418 & 0.380 \\
\hline & [0.214] & [0.213] & [0.969] & [0.945] \\
\hline \multirow[t]{2}{*}{ Dlargesize } & 0.066 & 0.067 & $2.132 * *$ & $2.102 * *$ \\
\hline & {$[0.288]$} & {$[0.286]$} & [1.060] & [1.027] \\
\hline \multirow[t]{2}{*}{ npe } & $0.066 * * *$ & $0.066 * * *$ & $-0.321 * * *$ & $-0.321 * * *$ \\
\hline & [0.022] & [0.023] & [0.066] & [0.067] \\
\hline \multirow[t]{2}{*}{$\mathrm{cr}$} & -0.003 & -0.003 & -0.040 & -0.042 \\
\hline & [0.005] & [0.006] & [0.024] & [0.026] \\
\hline \multirow[t]{2}{*}{ sys } & -0.001 & -0.001 & 0.003 & 0.003 \\
\hline & [0.003] & [0.003] & [0.010] & [0.010] \\
\hline \multirow[t]{2}{*}{ marketcap } & $-0.009 * * *$ & $-0.009 * * *$ & $0.043 * * *$ & $0.045^{* * *}$ \\
\hline & [0.003] & [0.003] & [0.015] & [0.016] \\
\hline \multirow[t]{2}{*}{ level3 } & 0.038 & 0.038 & -0.158 & -0.150 \\
\hline & [0.061] & [0.061] & [0.209] & {$[0.221]$} \\
\hline \multirow[t]{2}{*}{ Drestruct } & 0.033 & 0.032 & -0.721 & -0.722 \\
\hline & [0.201] & [0.201] & {$[0.721]$} & {$[0.725]$} \\
\hline \multirow[t]{2}{*}{ Dirb } & -0.087 & -0.088 & $-1.382 *$ & $-1.333^{*}$ \\
\hline & [0.193] & [0.195] & [0.707] & [0.700] \\
\hline \multirow[t]{2}{*}{ Dcore } & 0.081 & 0.080 & -0.967 & -0.890 \\
\hline & [0.195] & [0.188] & [0.806] & [0.813] \\
\hline \multirow[t]{2}{*}{ rwa } & - & -0.001 & - & 0.014 \\
\hline & & [0.009] & & {$[0.032]$} \\
\hline \multirow[t]{2}{*}{ constant } & 0.676 & 0.694 & $-2.709 * *$ & $-3.194^{*}$ \\
\hline & [0.417] & [0.579] & [1.103] & [1.655] \\
\hline \multicolumn{5}{|c|}{ Collinearity diagnostics } \\
\hline VIF (mean) & 1.620 & 1.900 & 1.620 & 1.900 \\
\hline Condition index & 14.868 & 19.824 & 14.868 & 19.824 \\
\hline F statistic ( $p$-value) & 0.000 & 0.000 & 0.000 & 0.000 \\
\hline Adj R-squared & 0.292 & 0.286 & 0.888 & 0.887 \\
\hline Obs & 129 & 129 & 103 & 103 \\
\hline
\end{tabular}

Notes: Cluster-robust standard errors appear in parentheses. We use Stata13 for all calculations.

$*, * *, * * *$ indicate statistical significance of the parameters at the $10 \%, 5 \%$ and $1 \%$ significance levels respectively. 